استراتيجية تطوير ممارسة القيادة من خلال الحوكمة الرشيدة حسب تصورات أعضاء هيئة التدريس يِ جامعة

\author{
الطائف \\ ليلى محمد أبو العلاء” \\ جامعة الطائف، المملكة العربية السعودية

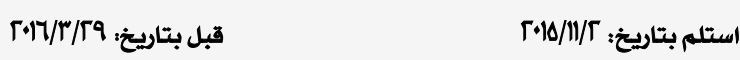

ملخص: هدفت الدراسة إلى اقتراح استراتيجية لتطوير ممارسة القيادة من خلال الحوكمة الرشيدة في جامعة الطائف

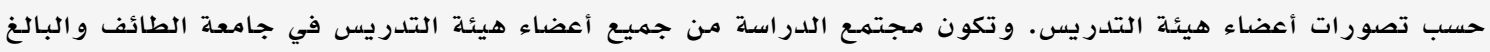

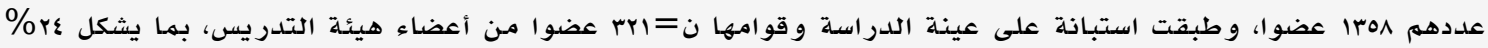

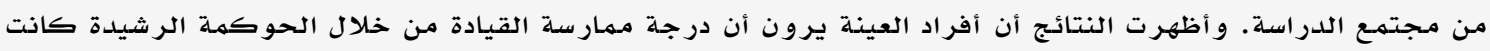

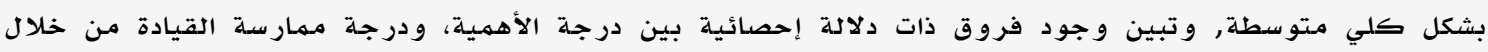

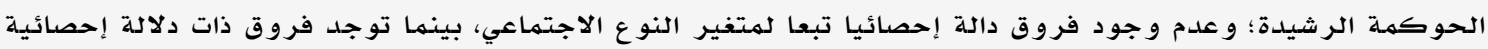

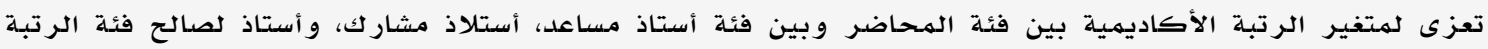

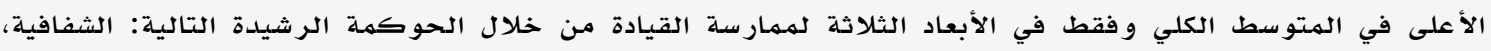

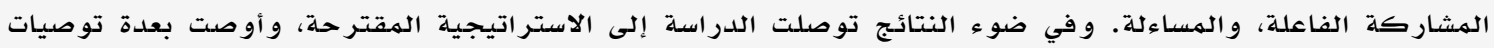

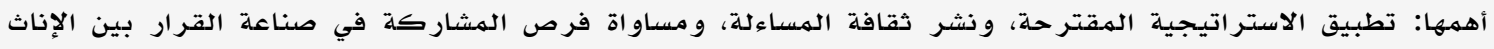

\title{
A Strategy for Developing the Leadership Practice through Wise Governance from the Viewpoint of Al Taif University Members
}

Laila M. Abo Alola

Taif University, Saudi Arabia

\begin{abstract}
The study aimed at proposing a strategy for developing the leadership practice in Taif University through wise governance. The study population included all faculty members at the Taif University which represented -1358- members. A questionnaire was administered tostudy a randomized sample which consist of -321 - faculty members which represented $-24 \%$ - of the study population. The findings showed that faculty members perceived the degree of practicing good governance generally as moderate. Also, the results showed statistically significant differences between the degree of importance and the degree of leadership practice through good governance. There were no statistically significant differences according to gender, but there were statistically significant differences according to academic rank in favor of the higher academic rank only in the following three dimensions of leadership practice through good governance: transparency, active participation, and accountability. In light of these results, a strategy was proposed which implied a number of recommendations, including: Application of the proposed strategy, spreading the culture of accountability, and providing equal opportunities for participation in decision-making for both men and women's departments.
\end{abstract}

Keywords: Governance, leadership, strategy, Taif University.

*L_aboalola@yahoo.com 
Finance Corporation)

من خلاله إدارة الشركات والتحكم في أعمالها" (Alamgir, 2007, p. 20)

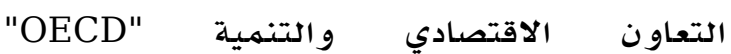
Organization for Economic Cooperation ) (and Development فيما بين القائمين على إدارة الشركة، ومجلس الإدارة، وحملة الأسهم (Cattrysse, 2005).

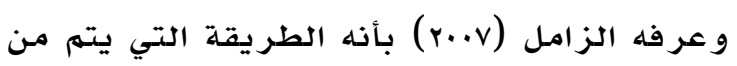

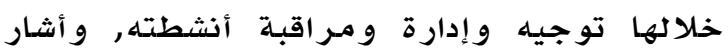

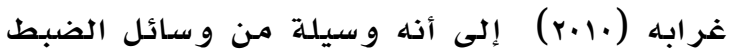

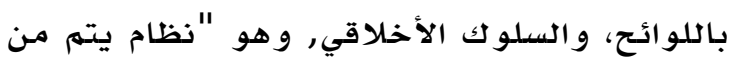

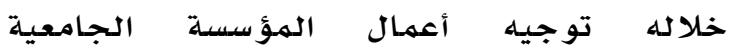

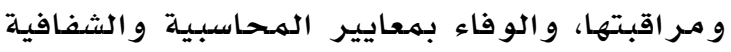

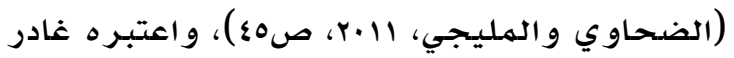

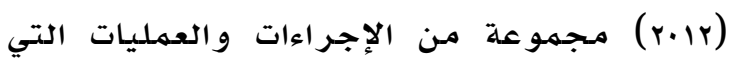

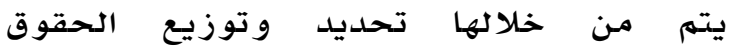
و المسؤو ليات على مختلف الأطر اف في الجامعة،

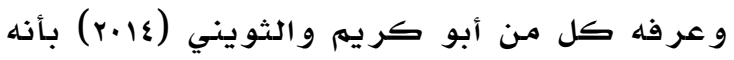

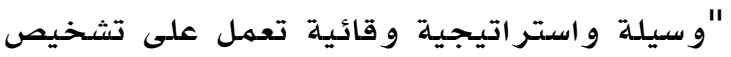

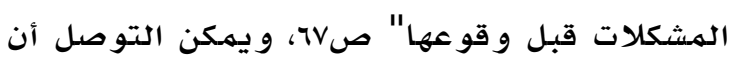

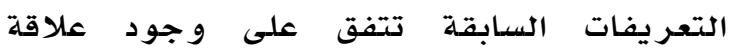
إيجابيه بين تطبيق المفهوم وتحقيق الجودة

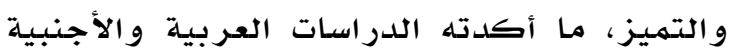

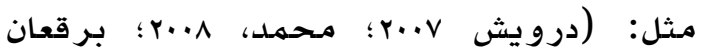

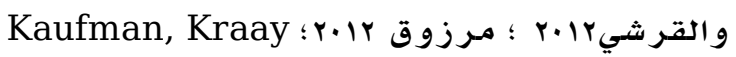
Hall \& Jones, 1999:Zoido, 1999 \& Acemoglu, Johnson \& Robinson, 2001: Freund, : Shattock, 2013: Wang, 2010: Beg, \& 2015: Rijkers, \& Nucifora 2014 (Ashok, التعليم الجامعي من خلال تعزيز المشاركة في لهادي

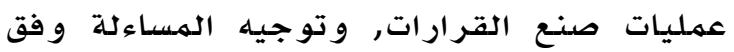

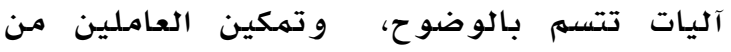

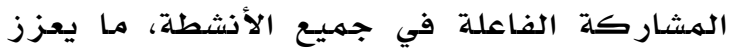
ثقافة الحوار بين مختلف منتسبي الجامعة جميعا كما ذكرت كوركوران بن مختف (Corcoran, 2004)، و أداة ضغط كبرى لتحسين الجودة في جميع

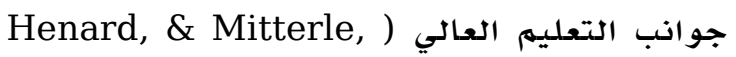

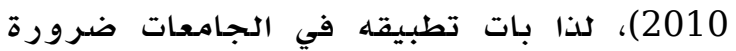

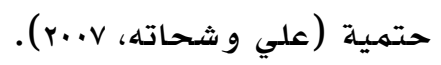

تعيث الجامعات عصر قوة المعرفة والبحث عن

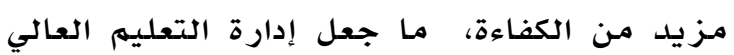

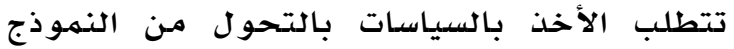

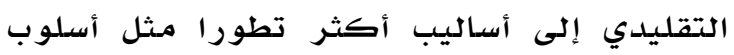

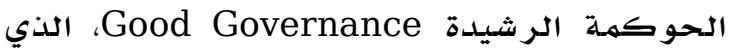

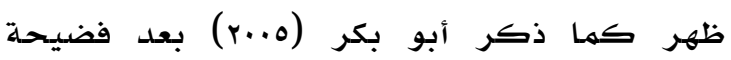

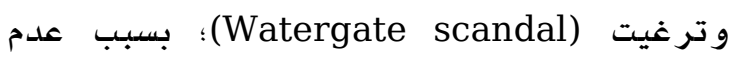
الرشد في الجوانب التنظيمية والإدارية، فحظي

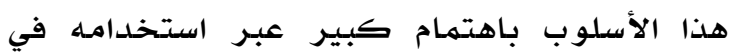
تحقيق التميز في الأداء الجامعي ( ) ل . (2010)

إن مفهوم الحوكمة من المفاهيم المثيرة للجدل حول ترجمته و تعريفه على نحو دقيق، فقد طرح

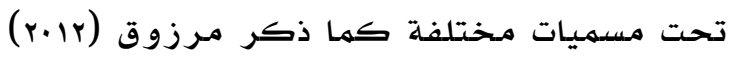
منها: حاكمية، وحكمانية، وإدارة شؤون الحكم،

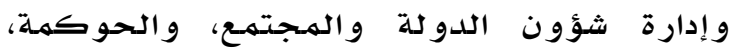

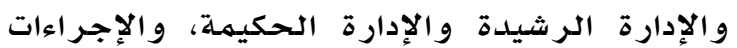
الحاكمة، وقد يرجع ذلك إلى حداثلة تطبيقه في الجامعات, إذ جاء ليعبر عن الأزمة التي دأي تتمثل في الفجوة بين الواقع والملموس لدوس (عطوة

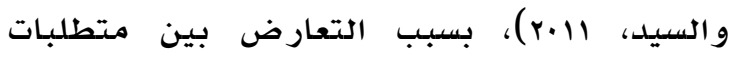

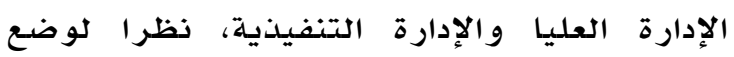

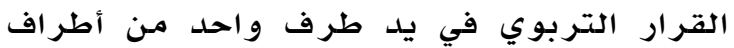

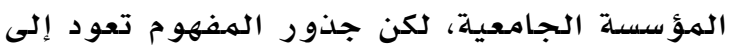

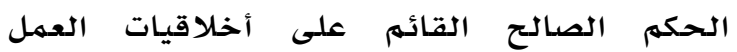

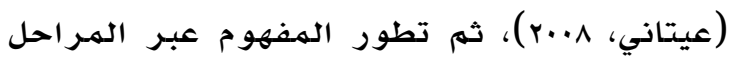

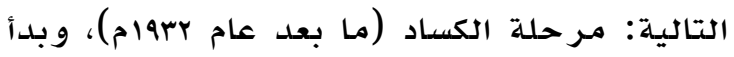
فيها الاعتر اف بعمق الفجوة بين الإدارة و الملاك

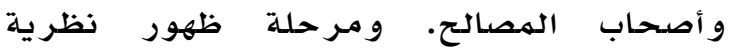
الوكالة وضبط العلاقة (19V7- 1990م)، والتي ولتي ظهرت فيها مطالب بشأن تنظيم العلاقات بين

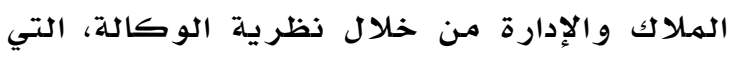

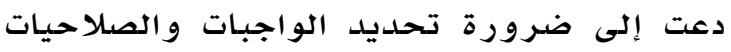

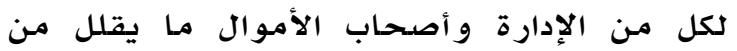

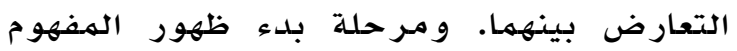

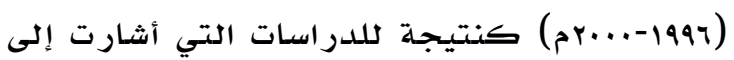
أسباب انهيار الثركات بسبب الإخفاقات الإدارية

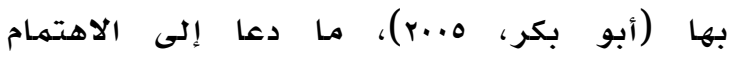

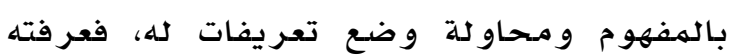

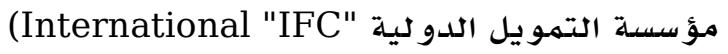


Lokuwaduge, Sriyani, and Armstrong, (2015) دراسـة بعنوان "تقييم آليـات الحوكمهـة

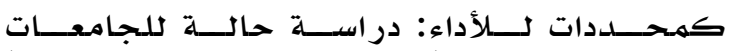

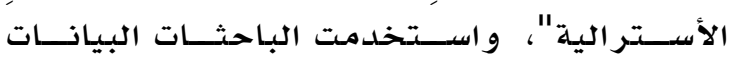

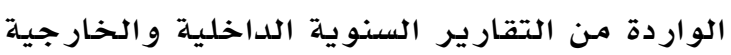

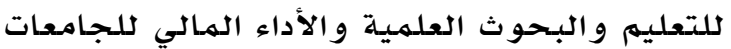

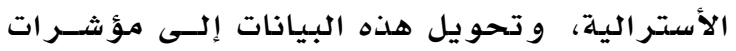

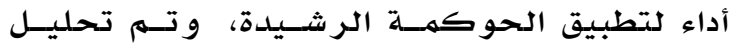

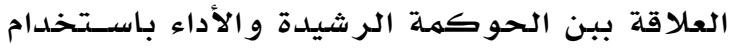

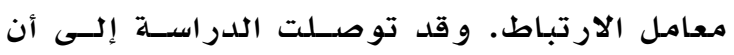

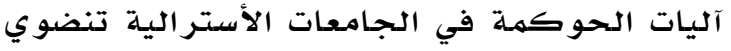

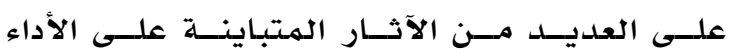
التعليهي و العلهي و المالي.

وقام بـيج و اشـوك (Beg and Ashok, 2015) بدراسة استكشافية هدفت إلى استكشاف معوقـات التهات

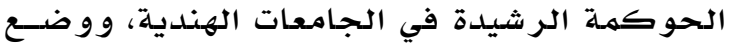

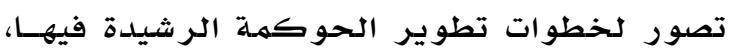

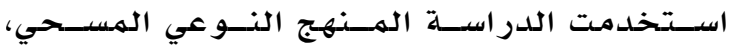

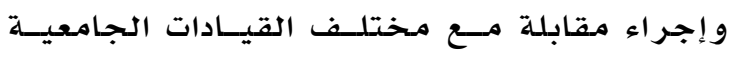

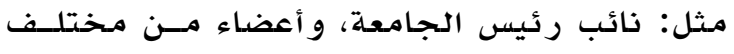

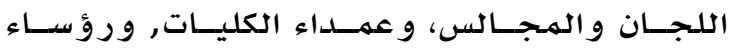

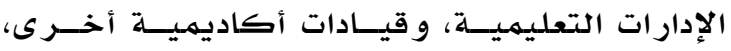

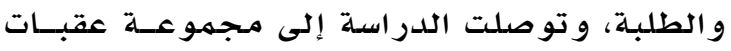

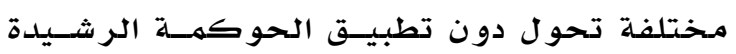

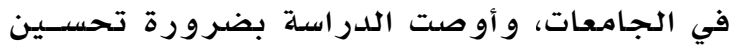

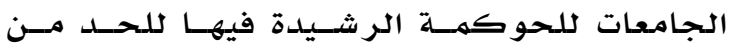

التحديات التي يفرضها اقتصاد المعر فة المقبل.

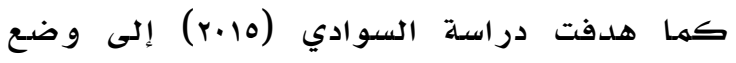

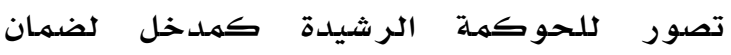

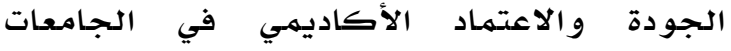

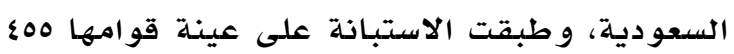

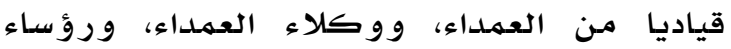

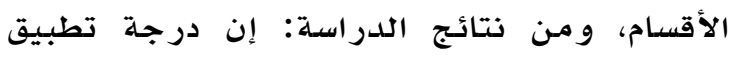

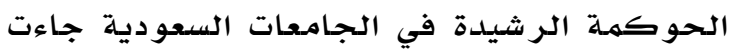
بدرجة ضعيفة. و أجرى أبو كريم و الثويني (\{1.ب) دراسة هدفت إلى معرفة درجة تطبيق مبادئ الحوكمة بكائ بكليات

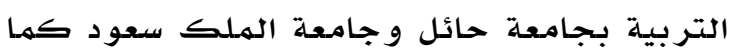

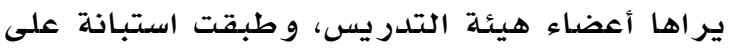

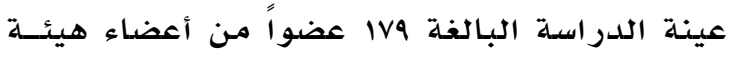

و يمكن القول أن المفهـوم يمثـل نظــام مناعسة،

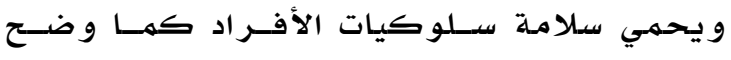

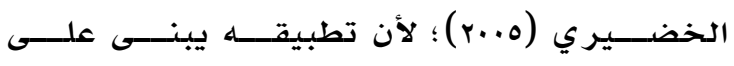

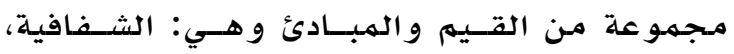

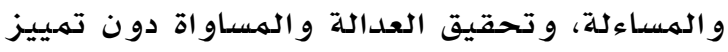
،Graham, Amos, \& Plumptre, 2003)

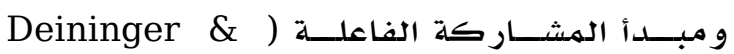
،Ferraz \& Finan, 2011: Mpuga, 2005

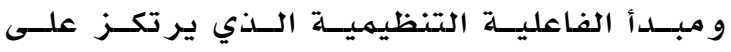

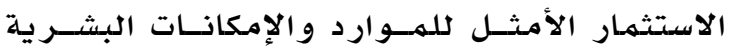
و المادية (العشماوي، 1..r). إن تطبيق مفهوم الحوكمة الرشيدة على الوجهـه

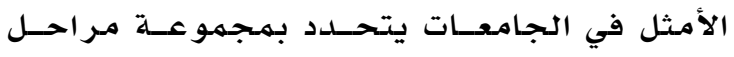

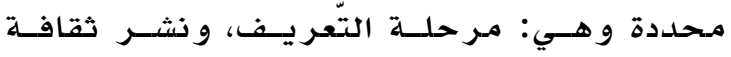

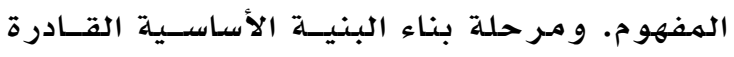

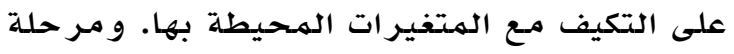

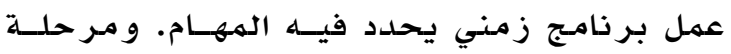

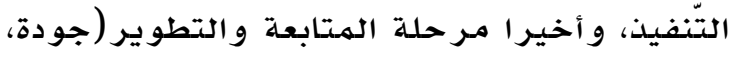

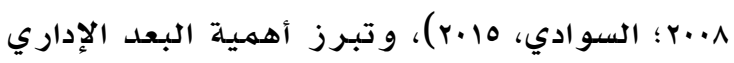

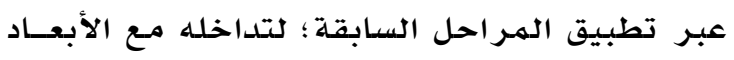

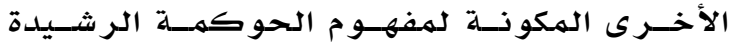

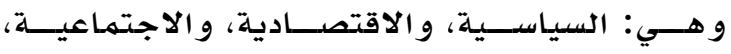

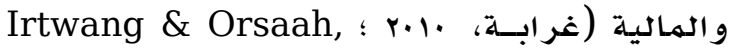
.(2010

و برزت أهميلة الحوكمهة الرشيدة فـي الجامعـات كمنهج لحماية الحقوق نشأ من علاقة الحوكهمة

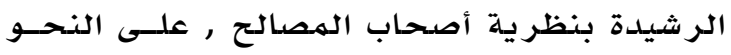

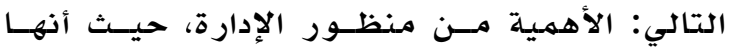
تعمل على تحقيق الجودة، وتجنب الفساد الهـالي

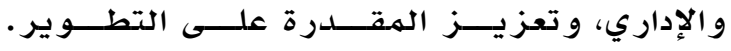

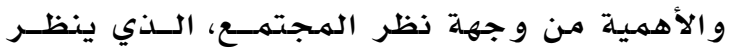
للحوكمة الر شيدة بأنها أداة رقابة و إثر اف ذاتي،

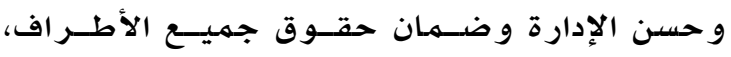
و بالتالي يتحقق رضا المجتمهـع عـن الجـامعــات. و تأتي الأهمية من وجهة نظر العاملين من كون

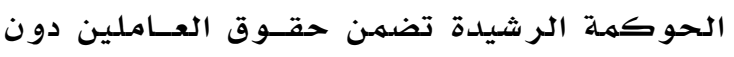

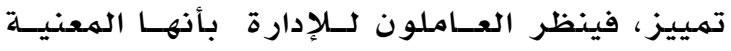

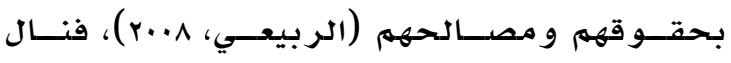

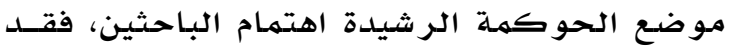
أجرت الباحثات لوميوديج وسرياني و آرمسترونغ 


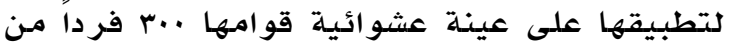

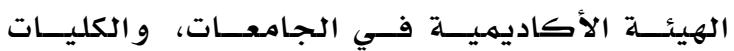

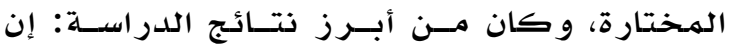

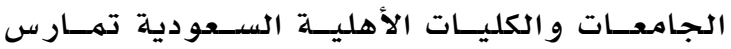
الحوكمة بلدرجة كبيرة.

و فـي محاو لــة لمعر فـة اتجاهــات أعضــاء هيئسة التدريس نحو نهج الحوكمة، ومعر فة مسـتويات مشــار كتهم فيسه، قامست كـل مسـن: كروبـال وكـوك (Krupar \& Cook, 2010) بـر اســة هدفت إلى التعرف على اتجاهــات أعضــاء هيئسة

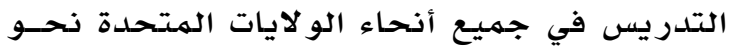

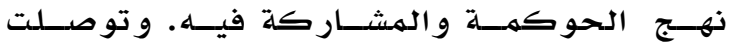
الدراسلة إلى أن أعضداء هيئة التـلدريس يواجهـون

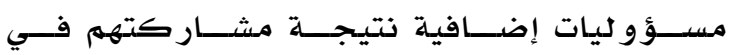
الحوكهمة، كما تتفاوت مستويات هذه المشار كة

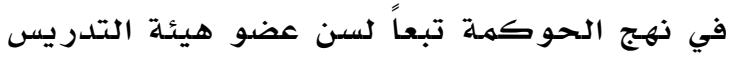
و لصالح الأكبر سناً. و هدفت دراسـة بر اتيـانو وو ينهـاردت و ألماسـان (Bratianu, Reinhardt, \& Almasan, 2010)

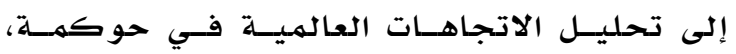
و إدارة التعليهم العالي في أوروبا، و ومسـى تطــور

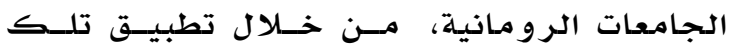

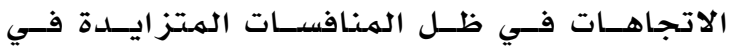

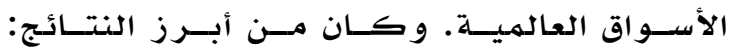

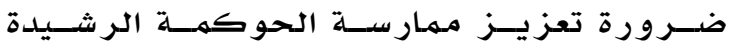
و الإدارة الفاعلة في مؤسسات التّعليهم العالي. وتوصل لانـــ و وـي (Lee \& Land, 2010) فــي دراستهما إلى معر فة واقع تطبيق الحوكمة فــي

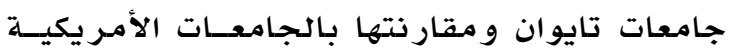

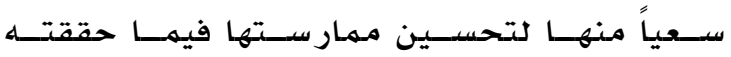

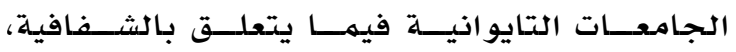
و الكلامر كزية، والمشاركة في الإدارة مسن قبـل

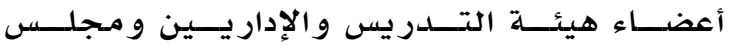

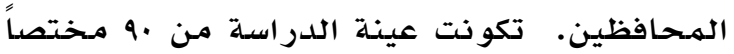
و قياديـاً فـي وزارة التر بيسة و التعلــيهم، و أعضــاء

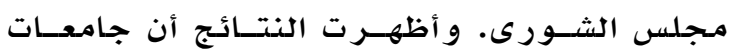
تايوان ما زالت في مر احل متأخرة في نضــــالها لتحقيـق التــوازن بــين الديمقر اطيــة و الكفــاءة

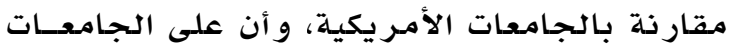

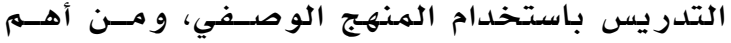

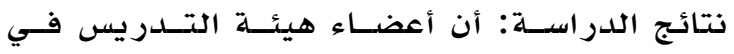

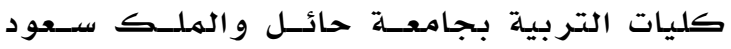
يرون أن تطبيق مبادئ الحوكمهـة بشـكل كلـي متوسط، و عدم وجود فروق دالــة إحصــائياً تبعـاً لمتغير الرتبـة العلميـة.

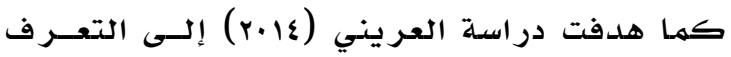

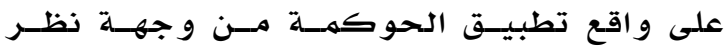

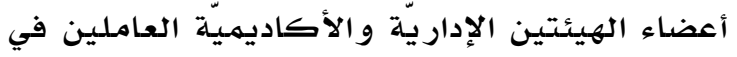

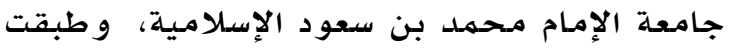

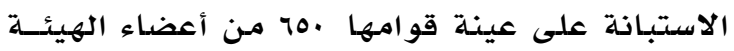
الإدارية و الأكاديهيلة، و قد أشـارت النتــائج إلــى: أن و اقـع تطبيسق الحووكمــة فـي جامعسة الإمسام

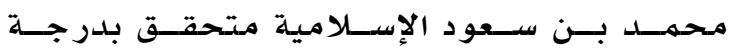
متوسطة، كما وجلدت الدر اسـة فروقـاً ذات دلادــة

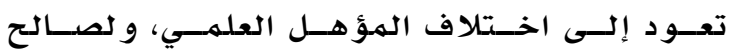

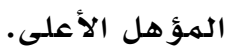
وقام كل من حلاوة وطه (r.r.r) بـر اسـة هـدفت

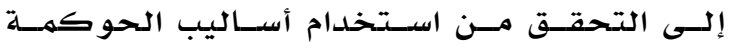

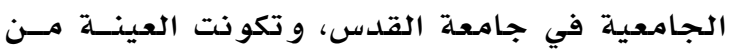

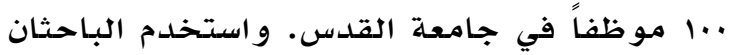

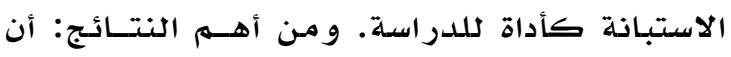

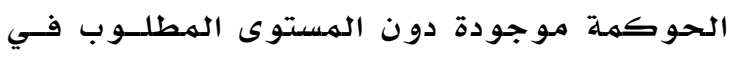
جامعة القدس وفق معايير الحوكمة كمة عالمياً. وقام ناصر الدين (r.lr) بإجراء دراسـة بعنـوان"

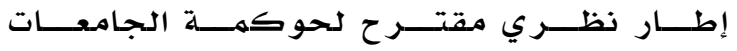

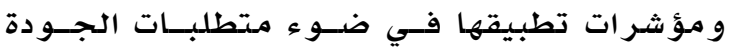

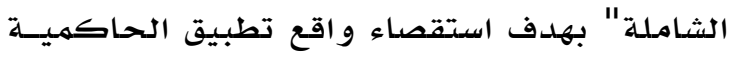
في جامعة الشرق الأوسط من وجهة نظر أعضداء

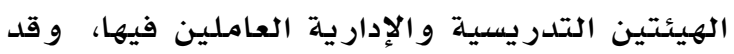

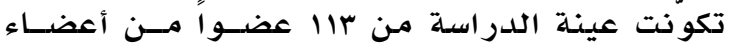

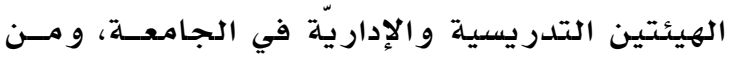

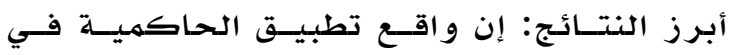

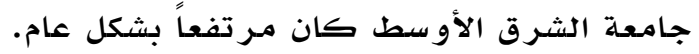
وهدفت دراسـة الزهر اني (11) إلى) إلى معر فة و اقع تطبيق الحوكمة الرشيدة في الجـامعـات الأهليـة

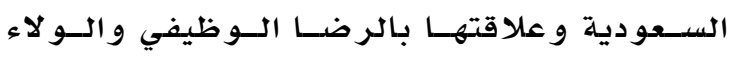

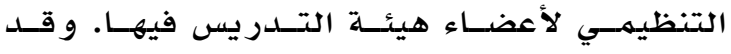

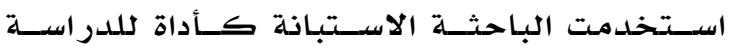


الحوكمهة، كان من العوامل التي أدت إلى تدني

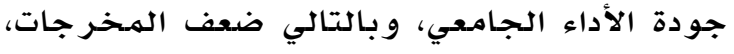

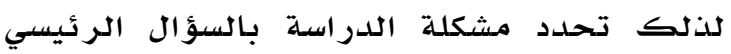
التالي: ما استر اتيجية تطوير ممارسة القيادة من من خلال الحوكمة الرشيدة حسب تصورات أعضاء هيئة التدريس في جامعة الطائفع وينبثق عنده الهوله الأسئلة الفرعية التالية:

ا. ما واقع ممارسة القيادة من خلال

الحوكمة الرشيدة في جامعة الطائف؟

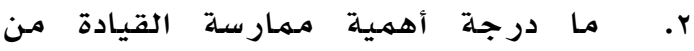

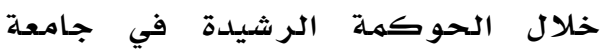
الطائف؟

r. هل هناك فروق ذات دلاكة إحصائية بين

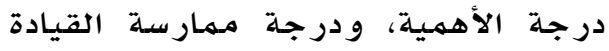
من خلال الحوكمة الرشيدة في جامعة ودئة الطائف؟

ع. هل هناك فروق ذات دلالة إحصائية بين متوسطات استجابة العينـة حول درجة دهربة

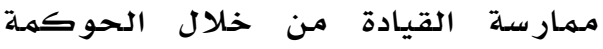

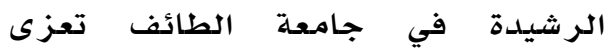

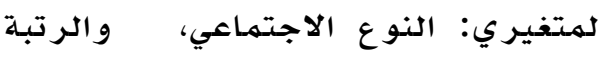

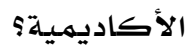
0. ما حاجة جامعة الطائف لتطوير ممارسة

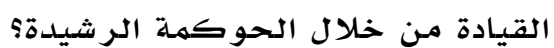
7. ما العناصر الرئيسة لاستر اتيجية تطوير

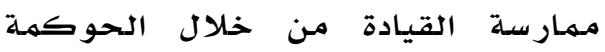

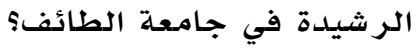

\section{أهداف الدراسة}

هدفت الدراسة إلى وضع استراتيجية مقترحة

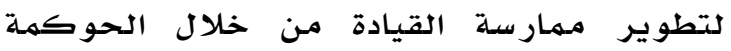

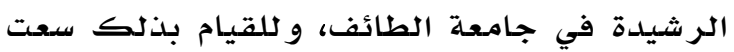
الدراسـة لتحقيق الأهداف التالية:

أولا: تشخيص واقع مهمارسة القيادة من خلال

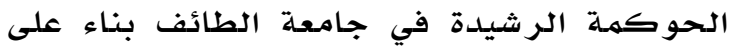
تصورات أعضاء هيئة التدريس. ثانيا: تحديد درجة أهميلة مهمارسة القيادة من

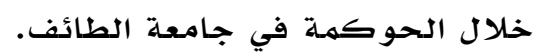

التايوانية العمل على تحسين أنمـوذج الحوكمــة

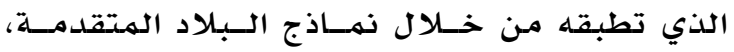

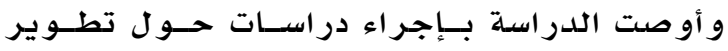
القيادات النسائية في إدارات التربية بية واءراءلتعليهم.

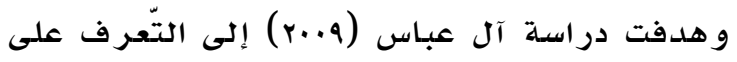

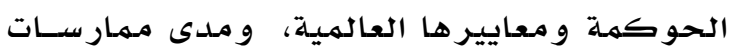

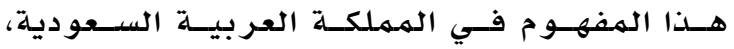

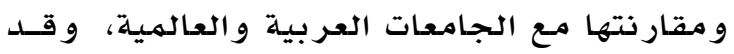

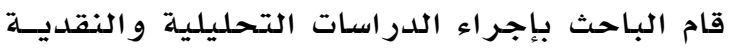

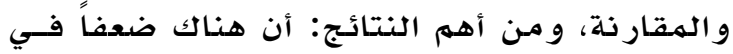
مستوى تطبيق الحوكمـة في الجامعات السّعودية بمقارنتها مـع الجامعات العالمية.

و يـلاحظ أن الدراسـة الحالية تتفق مـع الدراسات

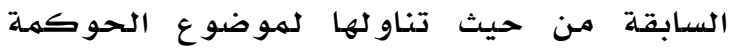

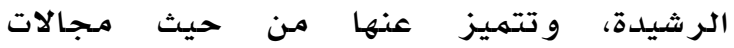
الهـوضدوع لكونها تهدف إلى وضع استراتيجية

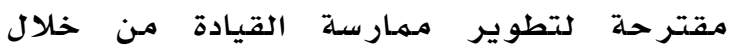

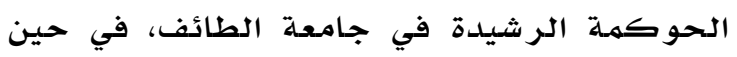

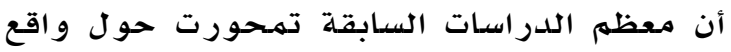

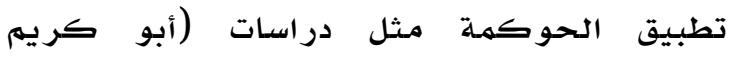

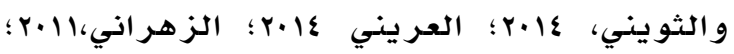

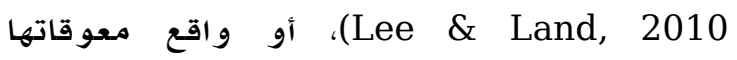
كدراسـة (Beg \& Ashok, 2015) أو تقوعييم Lokuwaduge et al., ) آلياتها مثل دراسة استة 2015)، و لا توجد دراسـة محلية سـابقة تناو لت دراسه

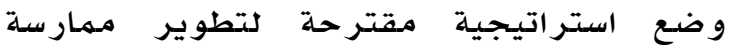

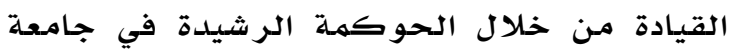
الطائف. و يمكن القول أن الدراسـات السـابقة أفادت

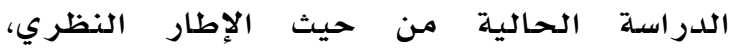
و المعالجة الإحصائية، و بناء الاستبانة.

\section{مشكلة الدراسة و أسئلتها}

تواجه الجامعات في المهملكة العربية السعودية العديد من التحديات التي أثرت على جودة

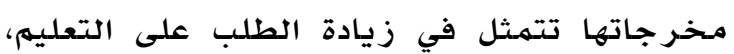
و مدى توافق الطاقات الاستيعابية لهذه الجـامعات

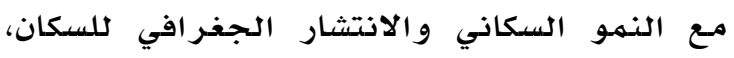
و في تشخيص دواعي تلك الهشكلات أثارت

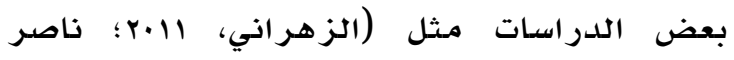

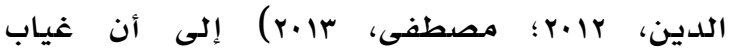




\section{حدود الدر اسة ومحدداتها}

الحد البشري: اقتصرت الدراسة على أعضاء هيئة

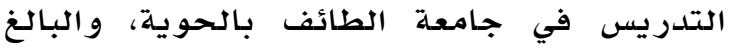

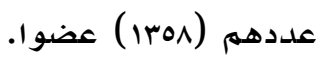
الحل الزمني: طبقت الدراسـة خلال الفصل الأول

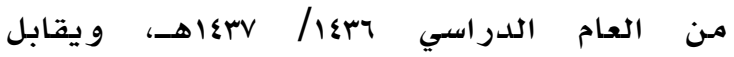
$\cdot r \cdot 17 / r \cdot 10$

محددات الدراسة: تتمثل محددات الدراسلة في

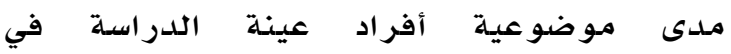
استجابتهم على فقرات المقياس لتشخيص واقع مولى

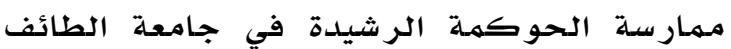

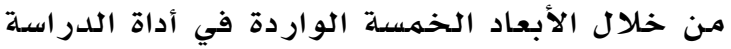
و هي: الشفافية، و المساءلة، و الفاعلية التنظيمية، و العدل و المساواة، و المشاركة الفاعلة. مصطلحات الدراسة والتعريفات الإجرائية: وردت في الدر اسلة التعر يفات الآتية:

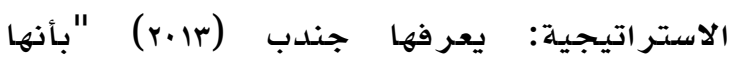
استشر اف المستقبل، وتقديه الفكرة المستقبلية، و توليد النشاطات اللازمة لتحقيق الفكرة بما

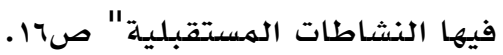

الاستراتيجية المقترحة: وتعرف إجرائيا: بأنها

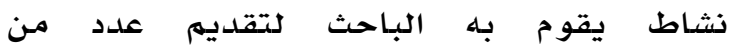
الهقترحات التي تسهم في تطوير مهمارسة القيادة

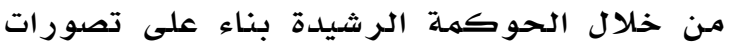

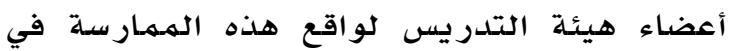
جامعة الطائف.

الحوكمة الرشيدة: يعرفها أبو النصر (10)

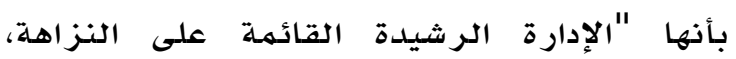

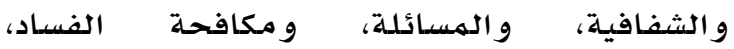

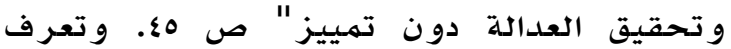
إجر ائيا بأنها: مقدرة جامعة الطائف على تحقيق

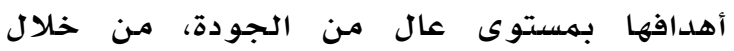

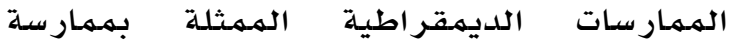

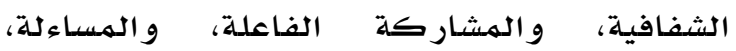
و العدل و المساواة، و الفاعلية التنظيهية. ويتم

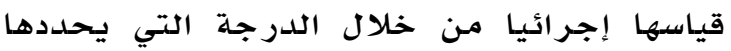

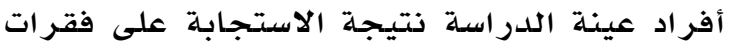

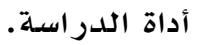

ثالثا: الكشف عن الفروق ذات الدلالة الإحصدائية بين درجة الأهمية، ودرجة ممارسة القيادة من الن خلال الحوكمة الرشيدة في جامعة الطائف. رابعا: الكشف عن الفروق ذات الدلالة الإحصائية بين متوسطات استجابة العينة حول درجة مهمارسـة القيادة من خلال الحوكهمة الرشيدة في

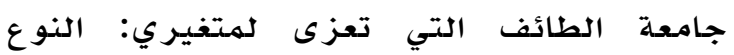
الاجتماعي، و الر تبة الأكاديميلة.

خامسا: تحديد حاجة جامعة الطائف لتطوير مـمارسـة القيادة مـن خلال الحوكمة الرشيدة، ثم وضع عناصر الاستر اتيجية المقتر حلة. أهمية الدراسة

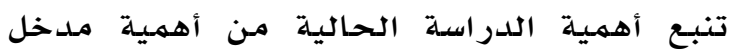

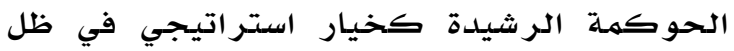

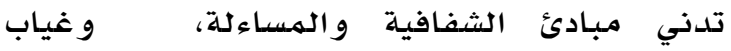
المشاركة المهتمعية في صناعة القرار الجامعي،

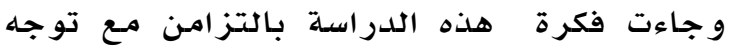
جامعة الطائف نحو الحصول على الاعتماد

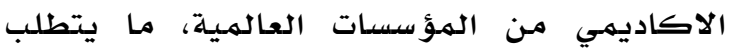

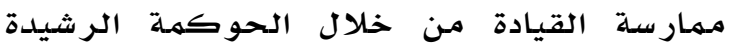

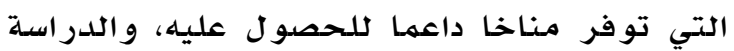

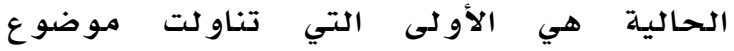
الحوكمة الرشيدة الذي يعد من التوليد التجديدات

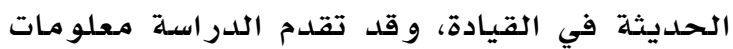
و تغذية راجعة عن واقع ممارسة القيادة من خلالد

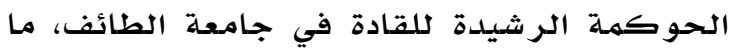
قد يساهم في تأدية مهامهم بشكل فعال، ويؤمل فئل

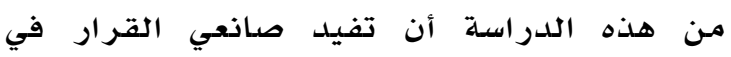
الجامعات السعودية، بالعمل على تطوير صناعة التهية

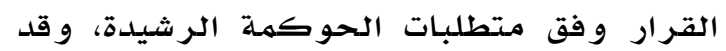
تفتح الباب لمزيد من الدراسات في هذا الهـال

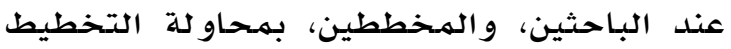

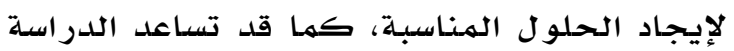
الطالبات؛ لأن تطوير مـمارسة القيادة من خلادل

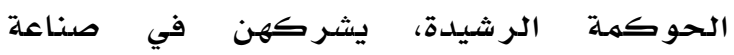

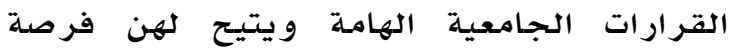

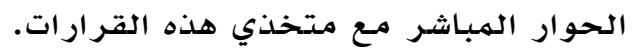


عشوائيا، وقد بلغ عدد الاستبانات المفقودة 11

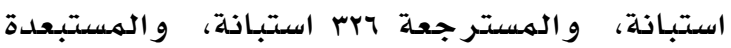

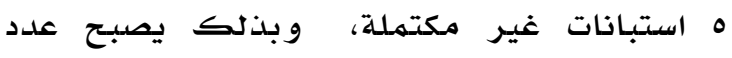

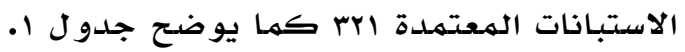

\section{جدول ا 1}

توزيع أفراد عينة الدراسة حسب متغيري: النوع الاجتماعي، والرتبة الأكاديمية

\begin{tabular}{|c|c|c|c|c|}
\hline \multicolumn{2}{|c|}{ عدد المستجييين } & \multicolumn{2}{|c|}{ عدد أفراد المجتمع } & المتغير \\
\hline النسبة المئوية & التكرار & النسبة المئوية & التكرار & متغير النوع \\
\hline$\% \uparrow \wedge, r$ & r19 & $\% 70,7$ & 191 & ذكر \\
\hline$\%$ \% & $1 . r$ & $\% \varepsilon \varepsilon, r$ & $\sum T V$ & أنثى \\
\hline$\%, \ldots, \ldots$ & ITI & $\%, \ldots, \ldots$ & Iron & المجموع \\
\hline النسبة المئوية & التكرار & النسبة المئوية & التكرار & متغير الرتبة \\
\hline$\% 19,7$ & זד - - (1) & $\% \uparrow 1, \wedge$ & raq & محاضر \\
\hline$\% \cdot 0 \cdot r$ & 171 & $\% \varepsilon\rceil, \cdot$ & Tro & أستاذ مساعد \\
\hline$\% 10,9$ & 01 & $\% r r, \varepsilon$ & $r \cdot \varepsilon$ & أستاذ مشارك \\
\hline$\% 1 \leqslant, r$ & $\leqslant 7$ & $\% ৭, \wedge$ & Tri & أستاذ \\
\hline$\% 1, \ldots$ & I & $\%, \ldots, \ldots$ & 1 1ron & المجموع \\
\hline
\end{tabular}

أداة الدراسة

تم تطوير استبانة لغايات الدراسة الحالية تحتوي

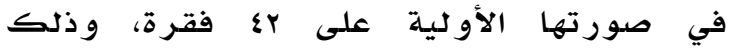
بالرجوع إلى الأدب النظري و الدراسات السابقة. و أعطي لكل فقرة وزنا متدرجا ورفا وفق مقياس

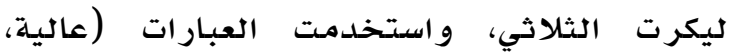

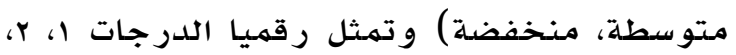
r على التوالي، و تألفت الاستبانة من قول قسمين:

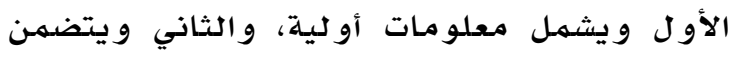
فقرات الاستبانة التي تمثل درجة مهمارسة التهل القيادة

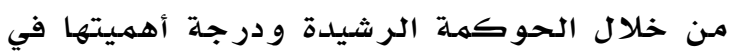
جامعة الطائف، وضهن الأبعاد الخمسلة التالية: الشفافية، و المشار كة الفاعلة، و المساءلة، و العدل الهال

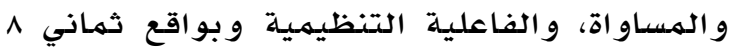
فقرات لكل بعد باستثناء بعد الفاعلية التنظيمية واهية الذي تضمن ·ل فقرات وذلك في الصورة الأولية

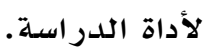

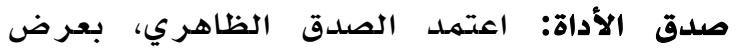
الأداة في صورتها الأولية على عشرة محكمين

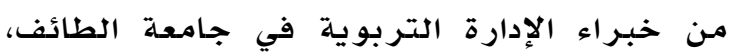
لإصدار حكمهم على مدى ملائمهة فقر ات الاستبانة
القيادة: "عملية التأثير و إلهاب الحمـاس في

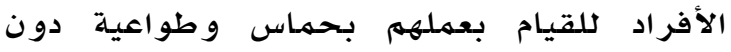

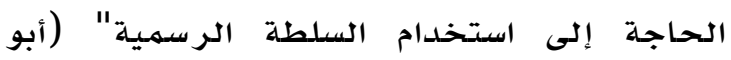

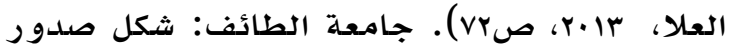

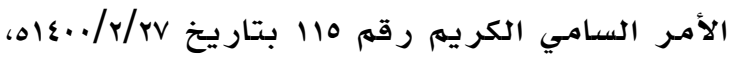

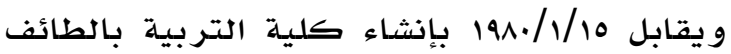
نواة التعليه الجامعي بالطائف، وكانت تابعة

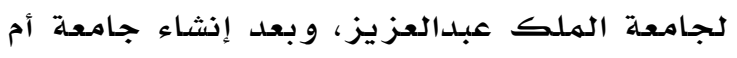
القرى صدر الأمر السامي الكريم رقم

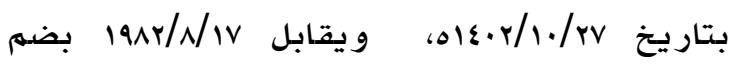

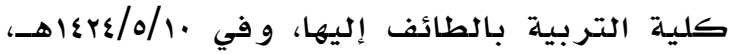

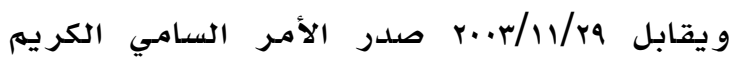

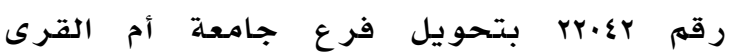

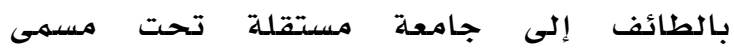

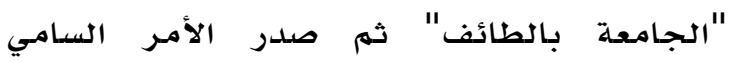

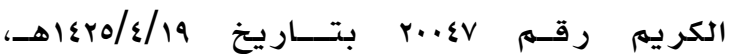

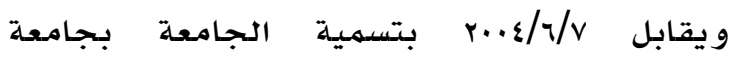

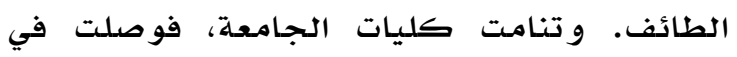

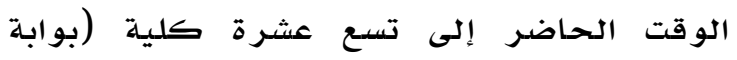

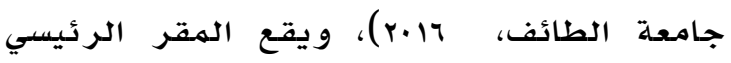
للجامعة في منطقة الحوية شهال مدينة الطائف.

\section{الطريقة والإجر اءات}

منهج الدراسة - - من

نهجت الدراسلة المنهج الوصفي التحليلي؛

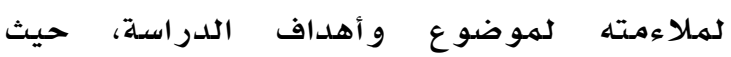
يتناول دراسـة أحداث وظواهر و مـمارسـات قائمة موجودة متاحة للدراسة والقياس كها هي دون

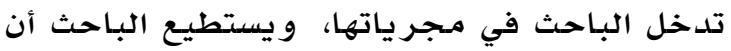

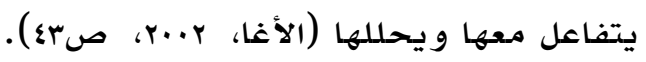

مجتمـع الدراسة

تكون مجتمـع الدراسة من جميع أعضاء هيئة

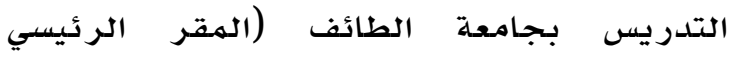

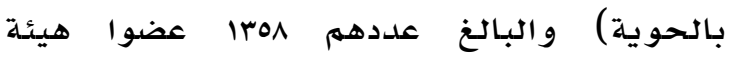

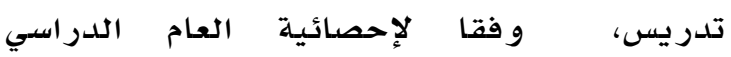
$\cdot r \cdot 17 / r+10$

عينة الدراسة

مثلت عينة الدراسة ما نسبته .\%\% من حجم

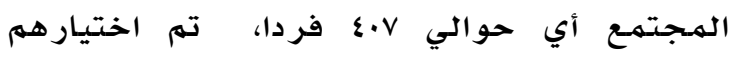




\section{النتائج ومناقشتها}

إجابة السؤال الأول ومناقشته: ما و اقع مـمارسة

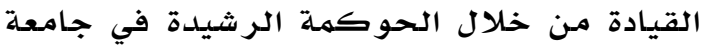
الطائفى يوضسح ملحق ا أن درجة مـمارسة أبعاد

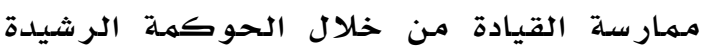
في جامعة الطائف متوسطة، بمتوسط كلي

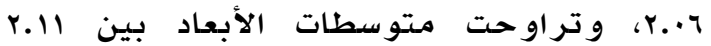
والو، 1.91، واحتل تطبيق بعد الفاعلية التتظيمية

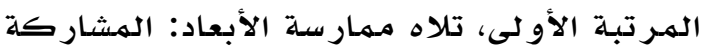

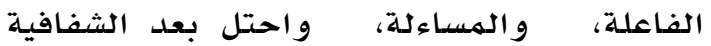

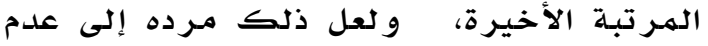
توفر القوانين التي تلدعم تطبيق الحوكمة في جامعة الطائف. و تتفق نتائج الدراسـة الحالية

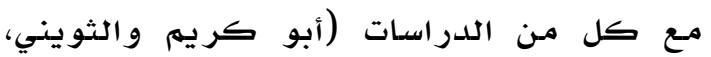

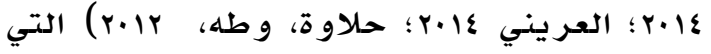
توصلت إلى أن الحوسمة تمارس بلدرجة متو سطة.

و بالهمجمل تتفق الدراسـة الحالية مـع دراسـة (آل

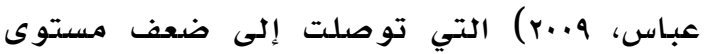
تطبيق الحوكمة في الجامعات السعودية،

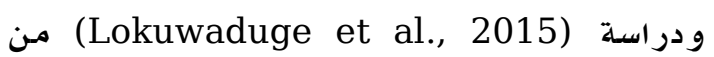
حيث أن تطبيق الحوكمة يؤثر على أداء الجامعة، ودراسة (Bratianu et al., 2010) التي توصلت إلى ضرورة تعزيز مـمارسة الحوكمة الرشيدة، وتخالف نتائج الدراسـة

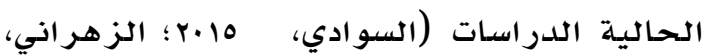

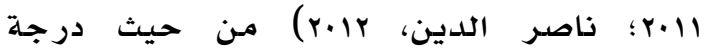

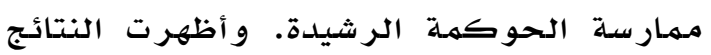
أن هناك تفاوتا في مستوى تأييد أفراد عينة الدراسـة لواقع تطبيق ممارسـة القيادة مـن خلالد

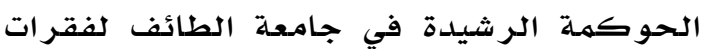
المقياس، بين عالية ومتوسطة و منتخفضة يوضحها ملحق الهيان والتفاصيل كالتالي: أو لا: الشفافية: جاءت مـمارسـة جميع فقر ات هذا المسجال جاءت متوسطة باستثناء الفقرتين:

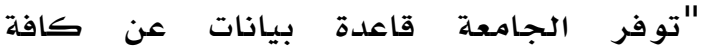

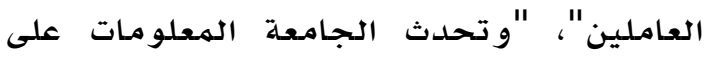

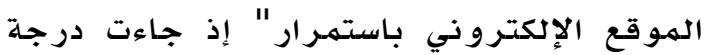

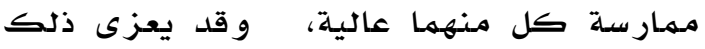

وسلامدة صياغتها، واعتمدد معيار •^\% كنسبـة اتفاق بين المحكمين لقبول الفقرة، وبناء عليه

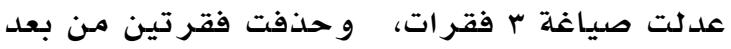
الفاعلية التنظيمية ليصبح عدد الفقرات النهائية •ع فقرة، وبواقع ^ فقر ات لكل بعد.

ثبات الأداة: تم حساب قيم معامل الاتساق الداخلي Cronbach's باستخدام معامل ألفا كرونباخ alpha

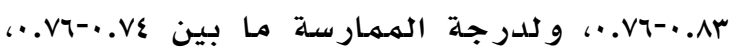

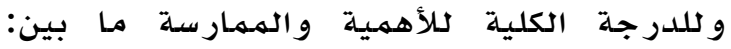

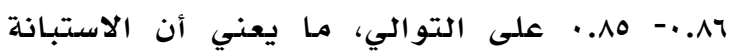
تتمتع بلدرجة ثبات عالية. | الإجر اءات

بعد الانتهاء من إعداد الاستبانة بصدر تها النهائية،

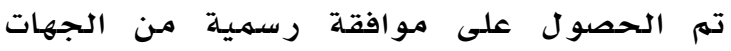
المعنية بتطبيق أداة الدراسة على أعضداء هيئة

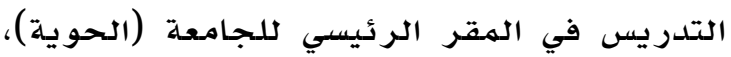

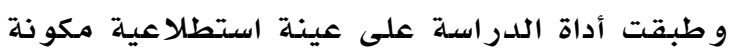
من ·r عضو هيئة تدريس استمدات من مهتهمع الدراسـة ومن خارج عينة الدراسة الحالية لغايات

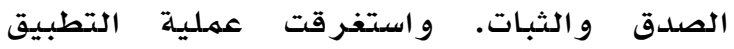
الميداني على عينة الدراسلة فترة ثلاثة أسابيع.

المعالجة الإحصائية بعد تفريغ الاستجابات، أجريت التحليلات الرلازمة للبيانات عن طريق الحاسوب باستخدام

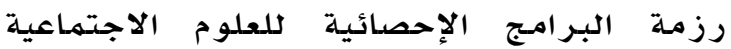

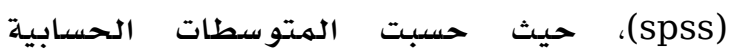

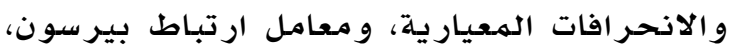

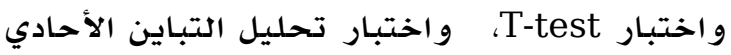

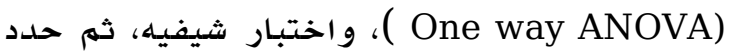

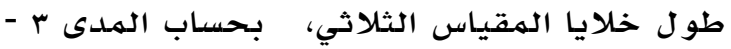

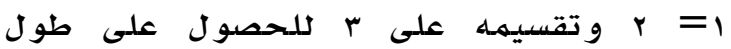
الخلية r r

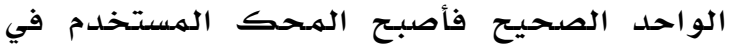
الدراسـة كما يلي: قيمة المتوسط الحسبابي أقل الحل من 1.TV تشير إلى معيار استجابة منخفضة،

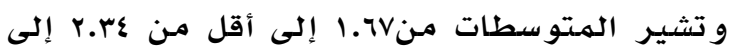

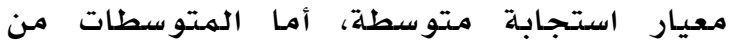
گr.r. إلى r فتشير إلى معيار استجابة عالية. 
الجامعة بالمستوى المطلوب، وعدم توجيهها لتشمل مساءلة مجالس الكليات عند ظهمور فجوة بين الأداء و النتائج المتوقعة ملهاءل

رابعا: العدل والمسـاواة: حظيت جميع فقرات هذا المجال بلدرجة مهـارسة متوسطة باستثناء

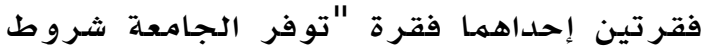

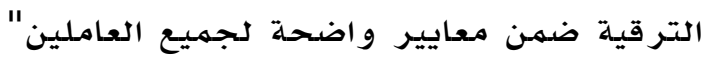

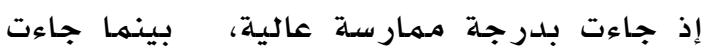

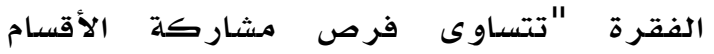

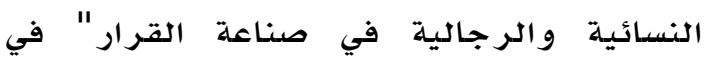

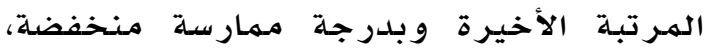
وقد يعزى ذلك إلى الترسبات الاجتماعية

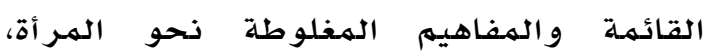
وهذا أمر مر فوض؛ لأن القيادة النسائية

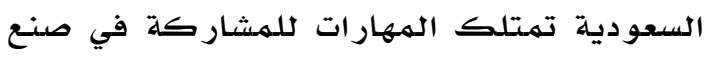

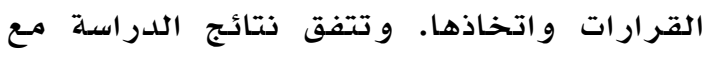
دراسة (Lee \& Land, 2010) التي أو صتح بإجر اء دراسات حول تطوير القيادات النسائية. خامسا: الفاعلية التنظيمية: جاءت تقديرات

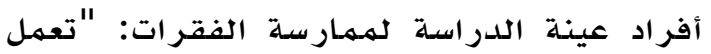

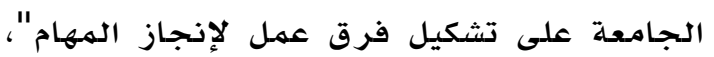

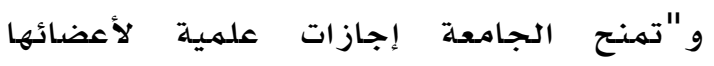

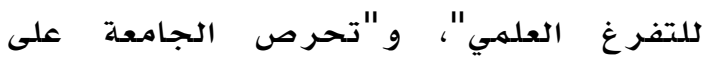

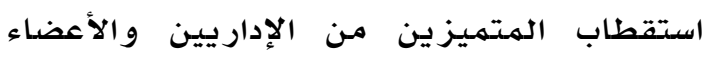
الأكاديميين"، و "تعمل الجـامعة على على تحقيق لإدارين أهدافها ضهن نقطة مثلى (أقل وقت وجهئ وجهد

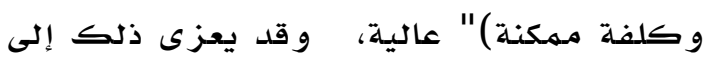
أن القيادات الأكاديمية في الجامعة تدرك بأنها معنية و ملززمة في توفير مناخ تنظيهي صحي

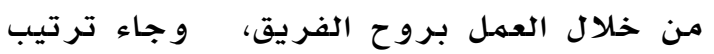

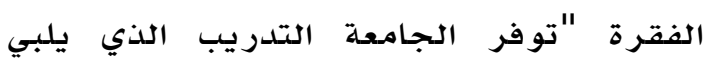

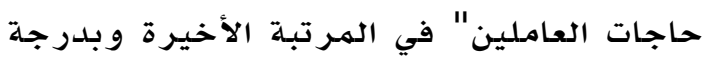

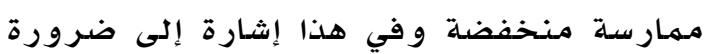
إعادة النظر في هذه البرامـج لتلبي احتياجـات العاملين. (العاده

إجابة السؤال الثاني ومناقشته: مـا درجة أهمية مـمارسة القيادة من خلال الحوكمة الرها الرشيدة

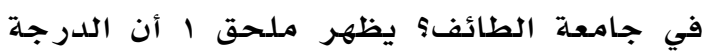

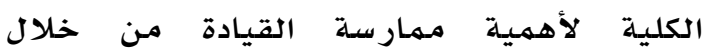

إلى توفر قناعة لدى قيادات الجـامعة بأهميلة

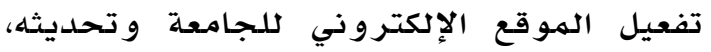

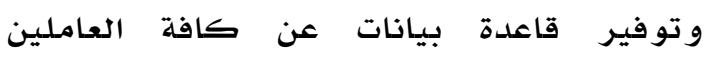

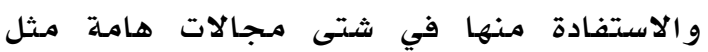
توفير إحصائيات دقيقة عن العاملين. ثانيا: المشاركة الفاعلة: حصلت الفقرات: "تشكل الجامعة لجانا مشتركة بين الأقسام الفارة لدعم العمل التشاركي"، و "تطبق الجـامعة مبدأ الشورى في إدارة أنشطة الكليات الهختلفة"،

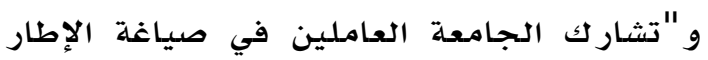

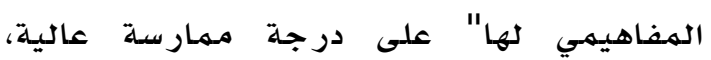
وقد يعزى ذلك إلى تطبيق القيادات الجامعية

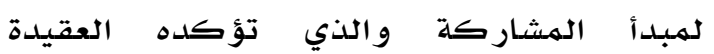

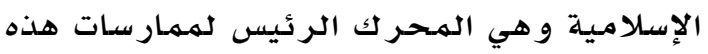

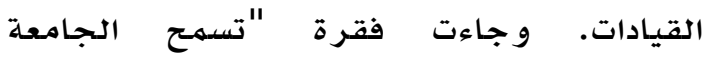

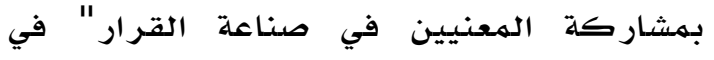

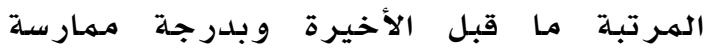

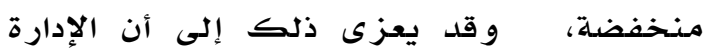

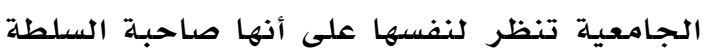

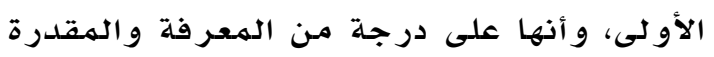

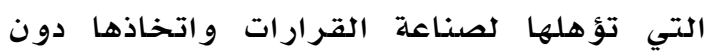

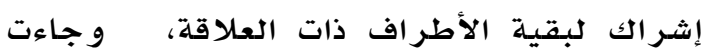
الفقرة "يشارك العاملون في تقييم القيادات

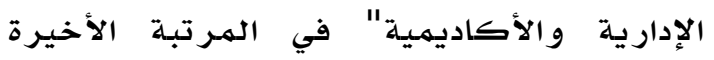

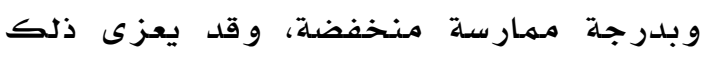

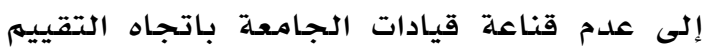
من أسفل إلى أعلى.

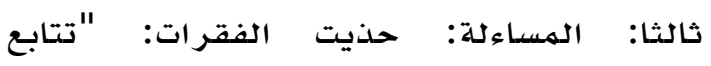
الجامعة التقارير الدورية الهنبثقة عن لجان الهان

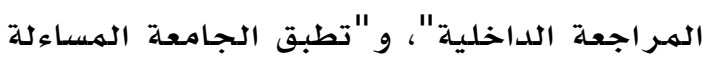

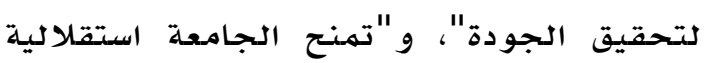

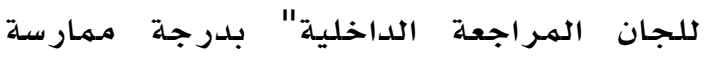
عالية، وهذه التقديرات متوافقة مـع توجهات جامعة الطائف وسعيها للحصول ولدهاه على الاعتماد الأكاديمي الذي يتطلب متابعة تقارير لجان

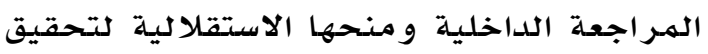

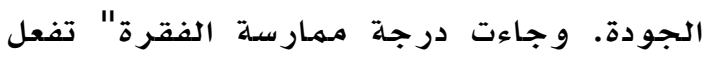

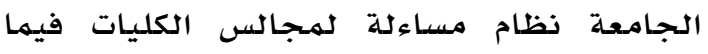

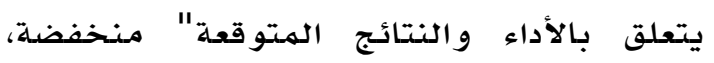
ويعزى ذلك إلى عدم نشر ثقافة المساءلة في 


\begin{tabular}{|c|c|c|c|c|}
\hline شيدة & حوكى لمتغ الغ & ق خلال & 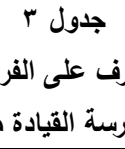 & الاجتماعي حور اختبار \\
\hline مستوى م & قيمة & درجات & النوع & المحور \\
\hline الدلالة الة & (ت) & الحرية & الاجتماعي & \\
\hline.$r$. & 1.00 & 419 & ذكر & الثفافية \\
\hline$\neg \varepsilon$. & $\cdot \wedge \varepsilon$ & 519 & ذكر & المشاركة الفاعلة \\
\hline .017 & $1 . \varepsilon$. & 519 & ذكر & المساءلة \\
\hline 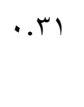 & $1 . .1$ & 419 & ذكر & العدل و المساو اة \\
\hline .ro & 9.90 & 519 & ذكر & الفاعلية التنظيمية \\
\hline . & $1 . r$. & 419 & ذكر & الأداة ككل \\
\hline
\end{tabular}

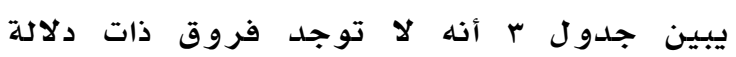

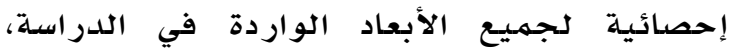

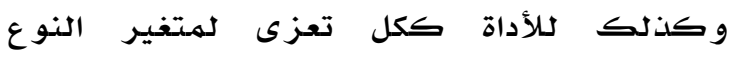
الاجتماعي، ويعزى ذلك إلى أن أساليب مـمارسة

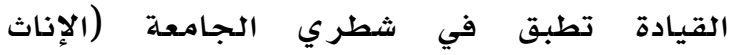
و الذكور ) و بالهنهجية نفسها دون تمييز بينهما. متغير الرتبة الأكاديمية: يوضت جلدول ع الهتوسط الحسابي والانحراف المعياري لإجابة

$$
\text { العينة حسب هذا المتغير . }
$$

الحوكمة الرشيدة في جامعة الطائف عالية،

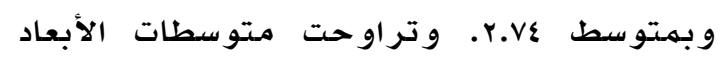

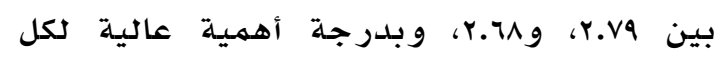

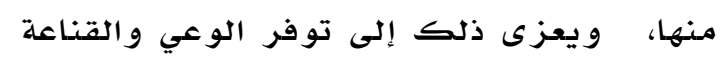

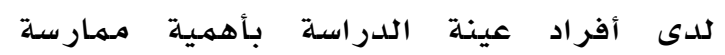
الحوكمة الر شيدة.

إجابة السؤال الثالث ومناقشته: هل هناك فروق

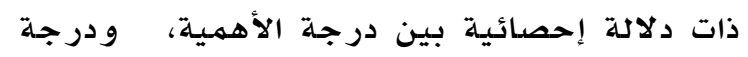

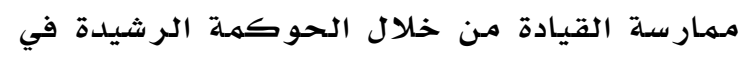

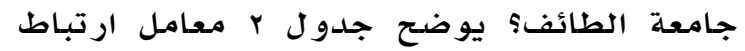

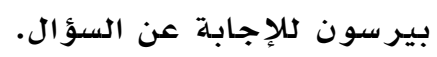
يوضح جدول r أن هنالك علاقة ارتباط داكة بين

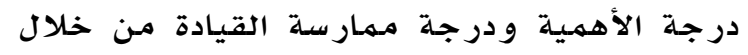

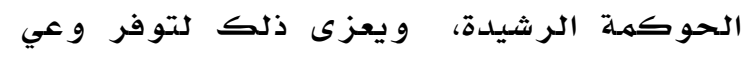

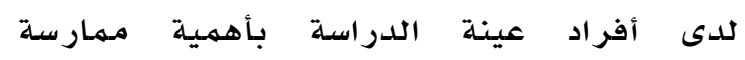
الحووكمة الرشيدة في الجامعة.

إجابة السؤال الرابع ومناقشته: هل هناك فروق ذات دلادة إحصائية بين متوسطات استوالجابـابة ومنابة العينة

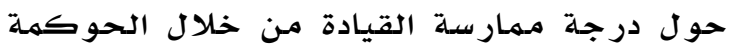

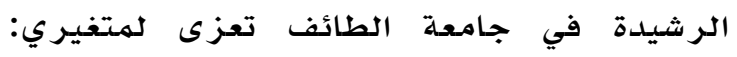
النوع الاجتمـاعي، و الر تبـة الأكاديميلة؟ متغير النوع الاجتماعي: يوضح جدول r نتائج

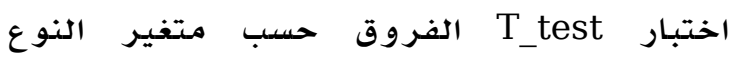

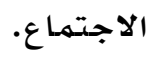

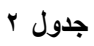

معامل ارتباط بيرسون لحساب الارتباط بين درجة ممارسة، ودرجة أهمية ممارسة الحوكمة الرثيدة في جامعة الطائف

\begin{tabular}{|c|c|c|c|c|c|c|}
\hline \multirow[b]{2}{*}{ الدرجة الكلية للبعد } & \multirow[b]{2}{*}{ الفاعلية التتظيمية } & \multicolumn{4}{|c|}{ أبعاد درجة ممارسة الحوكمة الرشيدة } & \multirow[t]{2}{*}{ بعاد درجة الأهمية } \\
\hline & & العدل والمساواة & المساءلة & المشاركة الفاعلة & الثفافية & \\
\hline$* *$ *.r & $* * .10$ & $* * .1 V$ & * & $* * . .1 r$ & $* * * r \varepsilon$ & الثفافية \\
\hline$* *$ *.ro & * * & $* * \cdot \cdot r$ & *** & ***..Tr & $* * . . r Y$ & المشاركة الفاعلة \\
\hline$* * \ldots 1 \leq$ & *** & 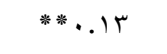 & *\%* & $*$. & $* * . .17$ & المساعلة \\
\hline 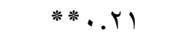 & *** & 米草 & * * & 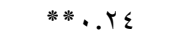 & *\%*.$r Y$ & العدل والمساواة \\
\hline$. .1 \leq * *$ &. $.17 \% *$ & ***..lr & $* \ldots \varepsilon$ & $* * \ldots 17$ & $* .$. & الفاعلية التنظيمية \\
\hline$* * . .17$ & 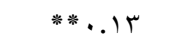 & $* * . .1 r$ & $* * \ldots 1 \varepsilon$ & $* * . .17$ & $* * \% 10$ & الأداة ككل \\
\hline
\end{tabular}




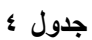

المتوسطات الحسابية والانحرافات المعيارية لإجابة عينة الدراسة حول درجة ممارسة أبعاد الحوكمة الرشيدة حسب الرتبة الأكاديمية

\begin{tabular}{|c|c|c|c|c|}
\hline الانحراف المعياري & المتوسط الحسابي & الت التكرار & الرتبة الأكاديمية & البعد \\
\hline.$r q$ & 1.91 & זי & محاضر & \\
\hline $.0 \varepsilon$ & r.11 & rז & أستاذ مساعد & \\
\hline$\therefore \leqslant 0$ & T.YA & 0 . & أستاذ مشارك & الثفافية \\
\hline .or & r.11 & $\leq 7$ & أستاذ & \\
\hline. .01 & $r .17$ & rr & الكلي & \\
\hline..$\leqslant \wedge$ & $1 . v$. & ז4 & محاضر & \\
\hline .07 & 1.90 & Tr & أستاذ مساعد & \\
\hline. .07 & r.11 & 0 . & أستاذ مشارك & المشاركة الفاعلة \\
\hline .0 & 1.91 & $\leq 7$ & أستاذ & \\
\hline .00 & $1.9 \pi$ & r & الكلي & \\
\hline$\therefore \leqslant 9$ & r... & ז4 & محاضر & \\
\hline $.0 \leqslant$ & r.11 & 174 & أستاذ مساعد & \\
\hline..$\leqslant 9$ & r.ro & o. & أستاذ مشارك & الثفافية \\
\hline .0 & r.11 & $\leq 7$ & أستاذ & \\
\hline $.0 r$ & r.IV & rr & الكلي & \\
\hline .0 . & 1.9 & זד & محاضر & \\
\hline $.0 \mathrm{~V}$ & r.. T & 174 & أستاذ مساعد & \\
\hline..$\leqslant \wedge$ & r.Ir & o. & أستاذ مشارك & المساءلة \\
\hline $.0 \mathrm{~V}$ & r.l. & $\leq 7$ & أستاذ & \\
\hline .00 & r...o & rr & الكلي & \\
\hline $.0 \%$ & $1 . \wedge \mathrm{V}$ & זד & محاضر & \\
\hline .7 & r... $\varepsilon$ & 174 & أستاذ مساعد & \\
\hline. $.0 \mathrm{~V}$ & 1.91 & o. & أستاذ مشارك & الفاعلية التتظيمية \\
\hline .or & $1.9 \mathrm{~V}$ & $\leq 7$ & أستاذ & \\
\hline. $.0 \mathrm{~V}$ & 1.99 & rr & الكلي & \\
\hline a & 1.19 & זי & محاضر & \\
\hline .0 & r... & 174 & أستاذ مساعد & \\
\hline T & r.IV & o. & أستاذ مشارك & الأداة ككل \\
\hline$\therefore \leqslant V$ & r... & $\leq 7$ & أستاذ & \\
\hline..$\leqslant V$ & r.. T & rr & الكلي & \\
\hline
\end{tabular}

يبين جلدول ه أنه لا توجد فروق ذات دلالة

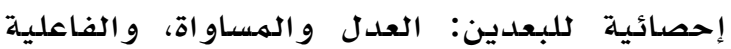
التتظيمية، بينها توجد فروق تلأبعاد الهتبقية تعزى لمتغير الرتبة الأكاديميلة، و لمعرفة اتجاه هذه الفروق، تم حساب اختبار شيفيه لهذه الأبعاد، و لكلأداة ككل، كما في فلدول
يبين جلدول ع أن هناك تباينا ظاهريا للهتوسطات

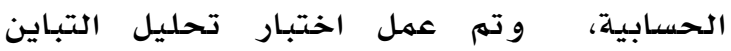
الأحادي (One way ANOVA) لهمر فة الدلادلة الإحصائية في جلدو ل 0. 
نتائج تحليل التباين الأحادي (ANOVA) للكثف عن دلالة الفروق بين متوسط الاستجابات تبعا لمتغير الرتبة الأكاديمية

\begin{tabular}{|c|c|c|c|c|c|c|}
\hline الدلالة الإحصائية & قيمة ف & متوسط المربعات & درجات الحرية & مجموع المربعات & مصادر التباين & 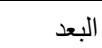 \\
\hline \multirow[t]{3}{*}{$* \ldots 1$} & r.vo & $.9 \varepsilon$ & r & T.AT & بين المجموعات & الثفافية \\
\hline & & .ro & riv & 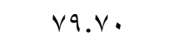 & داخل المجموعات & \\
\hline & & & rr. & NT.OT & الكلي & \\
\hline \multirow{3}{*}{$* \ldots$} & $7 . .1$ & $1 . V \varepsilon$ & $r$ & 0.117 & بين المجموعات & المشاركة \\
\hline & &..$\times 9$ & MIV & $9 . .7 V$ & داخل المجموعات & الفاعلة \\
\hline & & & rr. & $90 . \wedge 9$ & الكلي & \\
\hline \multirow[t]{3}{*}{$* \ldots 1$} & $\varepsilon . \mu$ & 1.10 & r & r. & بين المجموعات & المساءلة \\
\hline & &.$T V$ & MIV & AE.rI & داخل المجموعات & \\
\hline & & & rr. & NV.T & الكلي & \\
\hline \multirow[t]{3}{*}{. .14} & 1.91 &. .01 & r & l.vor & بين المجموعات & 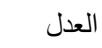 \\
\hline & & .r. & MIV & qr.s. & داخل المجموعات & والمساواة \\
\hline & & & rr. & 90.10 & الكلي & \\
\hline \multirow[t]{3}{*}{$\because r V$} & $1 . r 1$ & . & r & $1 . \mathrm{KA \Lambda}$ & بين المجموعات & الفاعلية \\
\hline & & אח.. & MIV & 1.4 .91 & داخل المجموعات & التتظيمية \\
\hline & & & rr. & 1.0.r. & الكلي & \\
\hline \multirow[t]{3}{*}{$* \ldots 1$} & 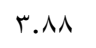 &.$\wedge \varepsilon$ & r & r.o. $\varepsilon$ & بين المجموعات & الأداة ككل \\
\hline & & . & riv & TA.YA & داخل المجموعات & \\
\hline & & & rr. & $\vee \cdot . \vee \wedge$ & الكلي & \\
\hline
\end{tabular}

جدول

نتائج اختبار شيفيه لتوضيح اتجاه الفروق في استجابة العينة لباقي أبعاد الحوكمة الرشيدة وفق الرتبة الأكاديمية

\begin{tabular}{|c|c|c|c|c|c|c|}
\hline \multicolumn{4}{|c|}{ الفروق بين المتوسطات } & \multirow{2}{*}{ المتوسطات الحسابية } & \multirow{2}{*}{ الرتبة الأكاديمية } & \multirow{2}{*}{ 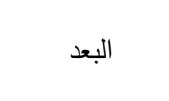 } \\
\hline أستاذ & أستاذ مشارك & أستاذ مساعد & محاضر & & & \\
\hline$* . r$ & $* . r$ & 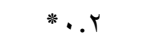 & - & 1.91 & محاضر & \multirow{4}{*}{ الثفافية } \\
\hline . & $\because 1$ & - & & r.11 & أستاذ مساعد & \\
\hline & - & & & T.YA & أستاذ مشارك & \\
\hline- & & & & r.11 & أستاذ & \\
\hline *.rA & *.. & *. ro & - & $1 . v$. & محاضر & \multirow{4}{*}{ لمشاركة الفاعلة } \\
\hline$\ldots r$ &. .17 & - & & 1.90 & أستاذ مساعد & \\
\hline. $.1 r$ & - & & & r.11 & أستاذ مشارك & \\
\hline- & & & & 1.91 & أستاذ & \\
\hline$* . .11$ & *.ro & $\% . .11$ & - & r... & محاضر & \multirow{4}{*}{ المساءلة } \\
\hline$\cdot$ & $\because \mathrm{V}$ & - & & r.11 & أستاذ مساعد & \\
\hline. $.1 V$ & - & & & T.TO & أستاذ مشارك & \\
\hline- & & & & r.11 & أستاذ & \\
\hline$\because . .19$ & $\because \cdot . r \wedge$ & $* . .19$ & - & 1.19 & محاضر & \multirow{4}{*}{ الأداة ككل } \\
\hline$\cdot$ & $\cdots 9$ & - & & r.. & أستاذ مساعد & \\
\hline$\cdots 9$ & - & & & T.IV & أستاذ مشارك & \\
\hline- & & & & r... & أستاذ & \\
\hline
\end{tabular}


و الوضع المرغوب فيه من خلال نتائج الدراسة، الأيجة

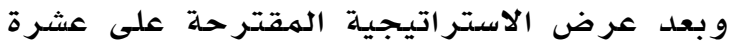

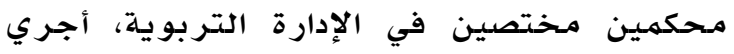

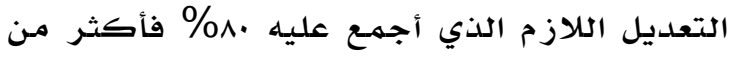

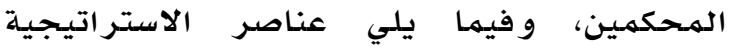
المقتر حة: الهحن، أو لاً: المقدمة: و تتضمن بهن بيان الحوكمة الرشيدة

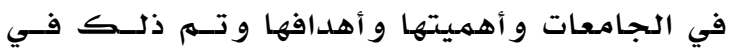

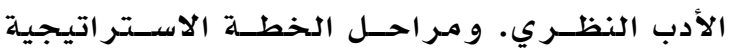

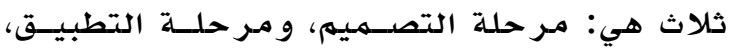

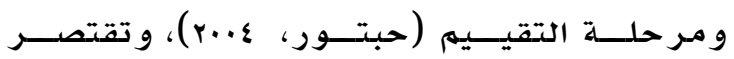

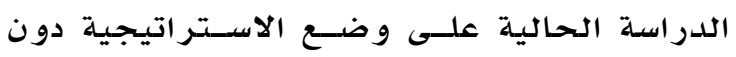
تقييمها، أي تقتصر على مرحلة التصــميم؛ لأن الن النهان عملية التقييم تأتي بعد التطبيق. ثانيا: الهدف العام: تمثل الهدف العام في تطوير

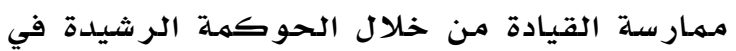
جامعة الطائف.

ثالثا: الأهداف الفرعية: وتتلخص الأهداف

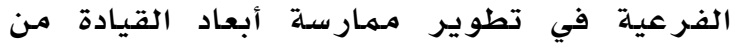
خلال الحوكمة الرشيدة الواردة في أداة الدراسة الدة الدادة

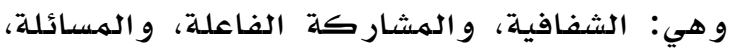
و العدل و المساواة، و الفاعلية التنظيمية. رابعا: منطلقات الاستراتيجية: وترتكز

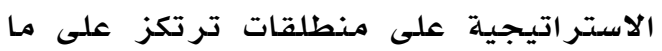
يلي:

الواقع الفعلي لممارسة القيادة من خلال الحوكمة الرشيدة، حيث أن النهائ النتائج أظهرت الحاجة لتطويره. اقتصار الدراسة الحالية على وضع

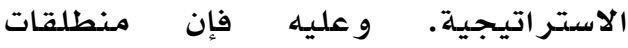

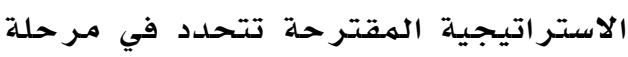

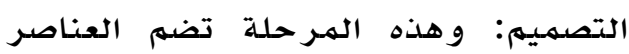

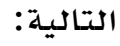

الرؤية المقترحة: تحقيق الريادة في

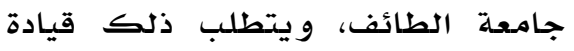
قادرة على استيعاب تغير ات المستقبل،

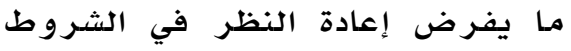
الواجب توافرها في قيادات الجامعة، إنة الثرطة
يظهر جدول 1 أن هناك فروقا ذات دلالة إحصائية بين متوسطات استجابة فئة محاضر من فرول

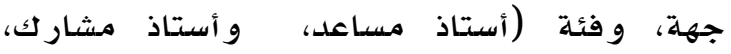

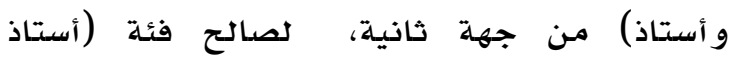

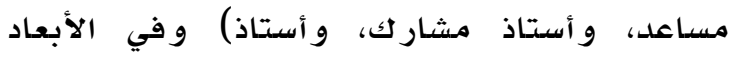

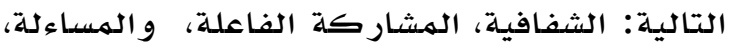

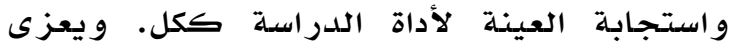
ذلك إلى أن الرتبة العلمية للفئة الثانية توفر الهران

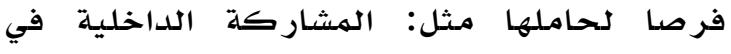

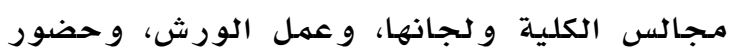

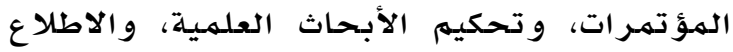

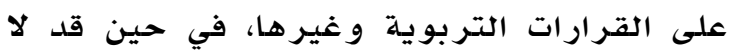
تتوفر مثل هذه الفرص للمحاضرين، وبالتالي التئي

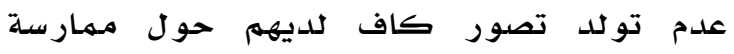
الحوكمة الرشيدة في الجامعة. وتتفق النتائج

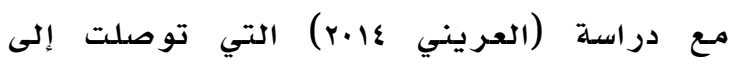

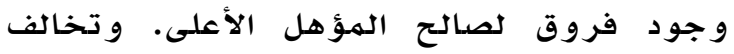

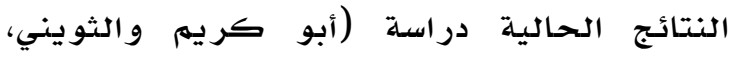

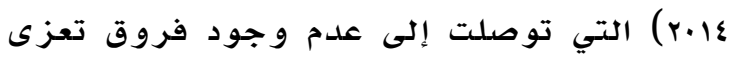
لمتغير الر تبة العلمية.

إجابة السؤال الخامس: ما حاجة جامعة الطائف

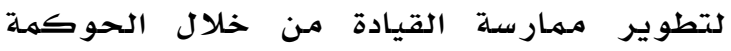

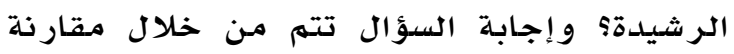

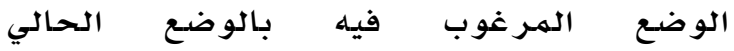
و وقد كان الفرق بين (Kaufman, 1982, 8)

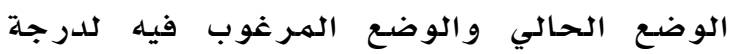

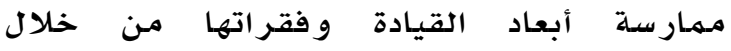
الحوكمة الرشيدة كما يظهر ذلك في الملحق

يظهر في الملحق r أن هناك حاجة لتطوير

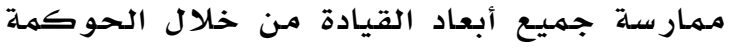

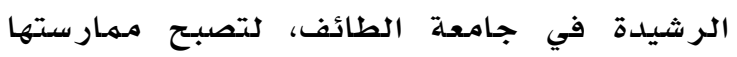
بدرجة عالية.

إجابة السؤال السادس: ما العناصر الرئيسة

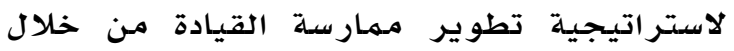
الحوكمة الرشيدة في جامعة الطائف؟ تتطلب

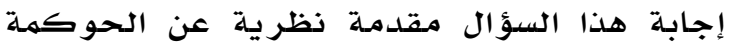

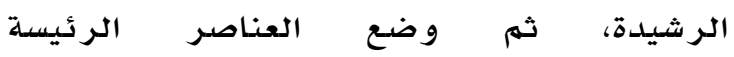

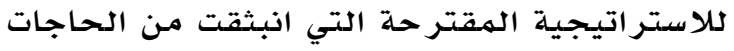

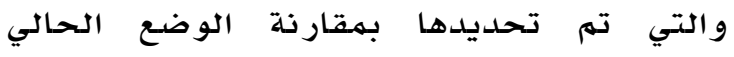


و التي تشكل الخطوط الرئيسة لحوطمة

الجامعات.

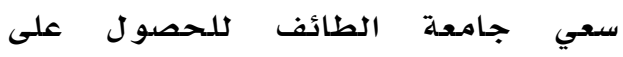
الاعتماد الأكاديهي.

سـادسا: مـر احل تطبيق الاستر اتيجية:

أولا: مرحلة التعريف: العمل على نشر ثقافة الحوكمة الرهيدة.

ثانيا: بناء بنية أساسية: بوضـع التشريعات

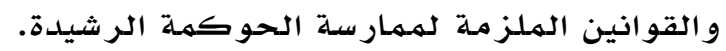
ثالثا: عمل برنامـج زمني لتتفيذ مـمارسـة أبعاد الحوكمهة الرشيدة. رابعا: مرحلة التتفيذ: مـمارسة أبعاد القيادة من

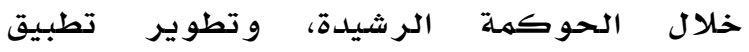

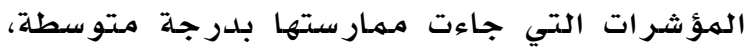

و منتخفضة.

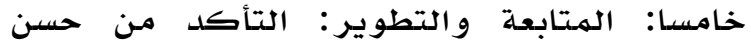

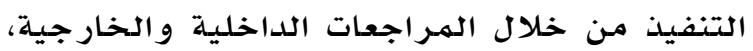
و تقديم التوصيات التطويرية لتطبيق الحوكمة الرشيدة بلدر جـة عالية.

\section{التوصيات}

توصي الدر اسـة بتطبيق الاستر اتيجية، و مـراعاة مـا يلي:

نشر ثقافة المساءلة في جامعة الطائف خاصلة فيما يتعلق بتوجيه المساءلة دون

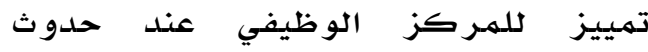
الانحر افات في الأداء.

مشاركة العاملين في صناعة القرار، ووفي تقييم القيادات الإدارية و الأكاديميـة. مساواة فرص المشاركة في صناعة القرار

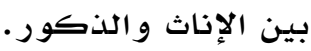

توفير التدريب الذي يلبي الكعاملين.

\section{المـراجع}

\section{References}

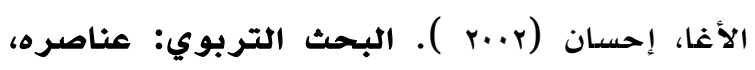

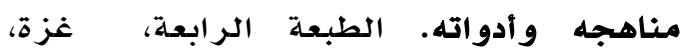
فلسطين: مطبو عات الجامعة الإسـلامية.
بما يتلاءم مـع مهارسة القيادة مـن خلال الحوكمهة الرشيدة. الاستعانة بأنهوذج (swot) الذاني كشف تقييم البيئة الداخلية لجامعدة الطائف من حيث ممـارسة القيادة من خلال الحوكمة الرشيدة، وتحديد نقاط القوة والضعف وهي كمها يلي:

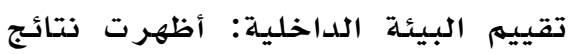

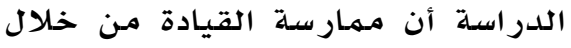

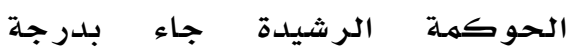
متو سطة. نقاط القوة:

وجود قيادات سعودية في الجامعة مؤهلة وقادرة على مـمارسلة القيادة مـن خلادل الحوركمة الرشيدة.

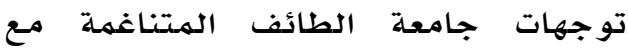
توجهات الدولة في تحقيق التنافسية العالمية في مجال التعليم العالي. تمويل التعليهم العالي من قبل الدو لة. نقاط الضعف:

عدم مشاركة أعضاء هيئة التدريس في جامعة الطائف بالدرجة الكافية في لئل العمليات التالية:

تقييم القيادات الإدارية و الأكاديمية. انتخاب الهـجالس العلمية. صنـع القرارات التربوية الهامـة. عدم توفر التدريب اللازم لأعضاء هيئة التدريس الذي يلبي احتياجاتهم. عدم مساواة فرص المشاركة في صناعة القرار بين الإناث و الذكور. خامسا: مبررات وضـع الاستر اتيجية: تمتلك القيادات في جامعة الطائف الهكونات الفكرية والثقافية التي تؤهلها لمواكبة تحديات العصر.

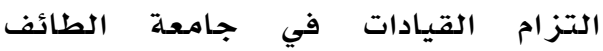
بالعقيدة الإسلامية، والأخلاق الفاضلة 
برقعان، أحمد؛ و القرشي، عبد الله (10/ديسمبر

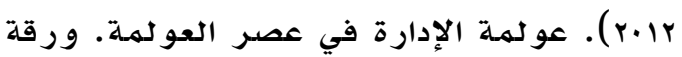
مقدمة إلى المؤتمر العلمي الدولي، المدارة المنعقد

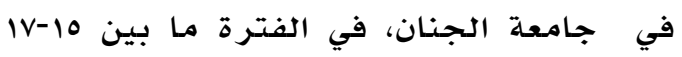

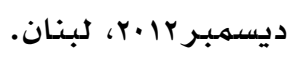

بوابة جامعة الطائف.(17 +r). التعريف بالجامعة.

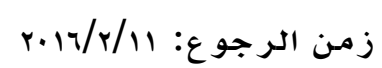

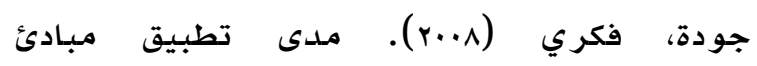

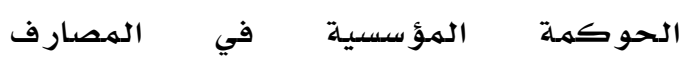

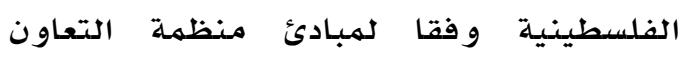

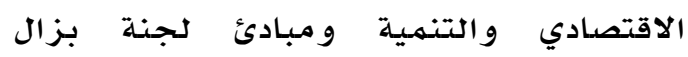

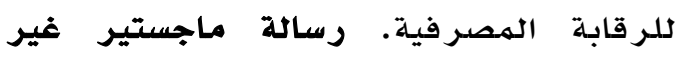
منشورة، الجامعة الإسـلامية، غزة، فلسطين. جندب، عبد الوهاب (r/r). أثر التوجهات

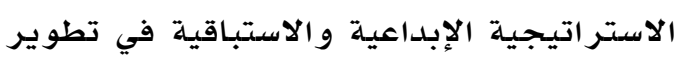

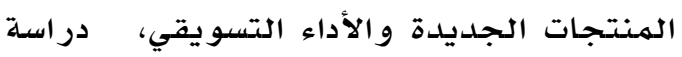

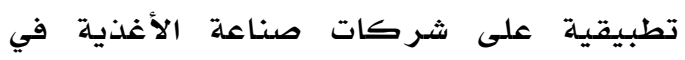
اليمن. رسالة ماجستير غير منشورة، جامعة

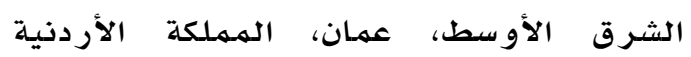

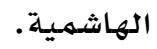

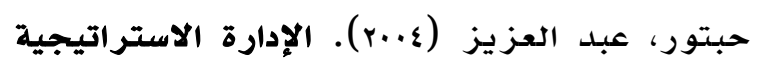

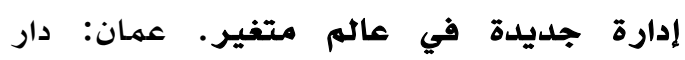
المسيرة للنشر . الماره

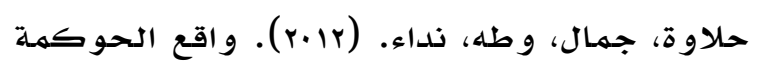

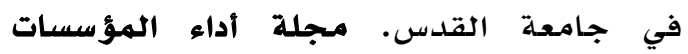

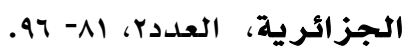

الخضيري محسن (r.o.o). حوكمة الشركات: كيف يتم تفعيل الرقاية الضميرية. القاهرة،

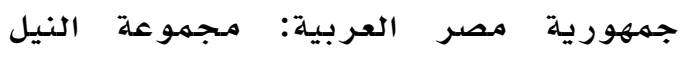

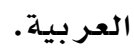

درويث، عدنان (r..v). حوكمة الشركات ودور

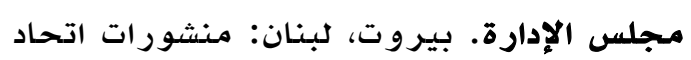

المصدارف العربية.

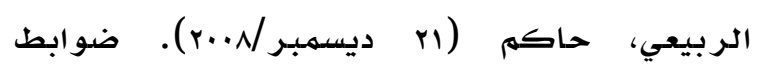
و آليات الحوكمة في المؤسسات الجامعية.

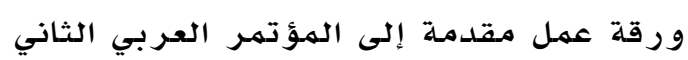

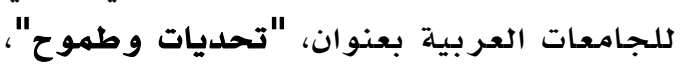

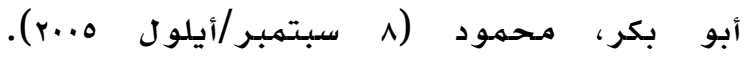

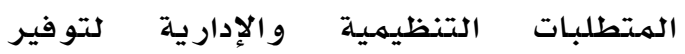

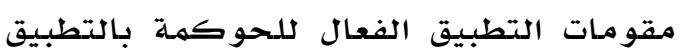

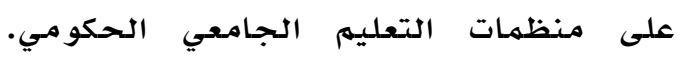

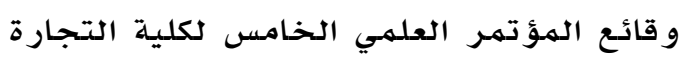

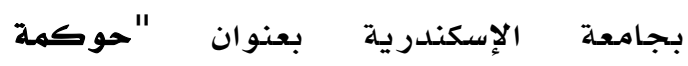
الشركات وابعادها المحاسبية والإدارية

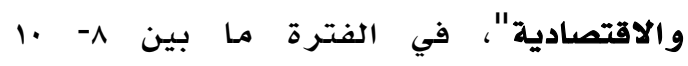

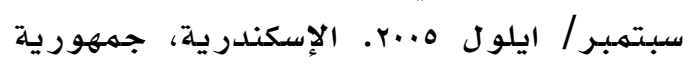
مصر العربية. أبو العلا، ليلى (rاrr). مفاهيم ورؤى في الإدارة

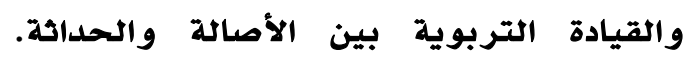

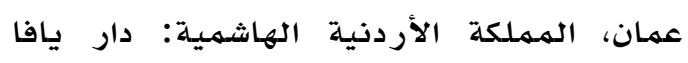
العلمية للنشر و التوزيع. أبو كريه، أحمد، والثويني، طارق (عا.ب). درجة الحئ

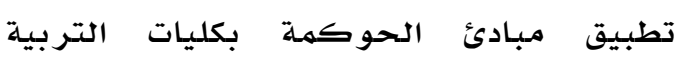

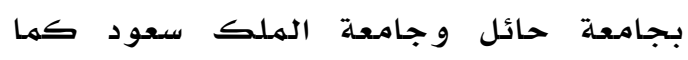

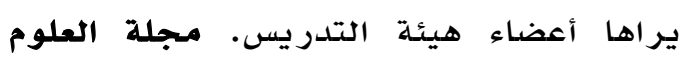

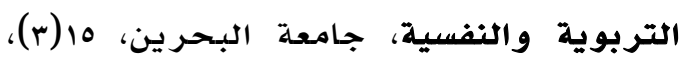
.9r-00 أبو النصر، مدحت (10 ب). الحوكمة الرثيدة: فن

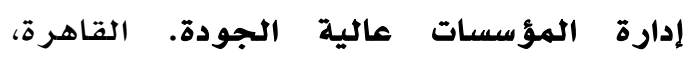

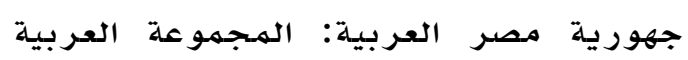
للتدر يب و النشر .

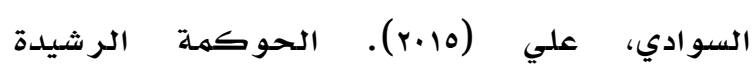

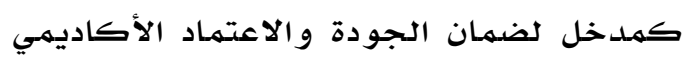

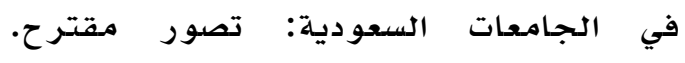

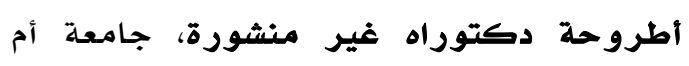

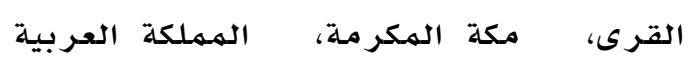

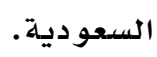
آل عباس، محمدد (اب أكتوبر/ تشرين الأول،

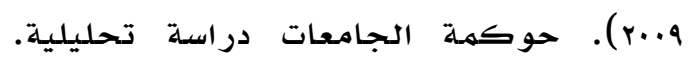

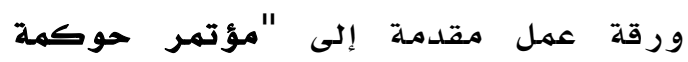

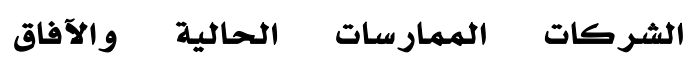

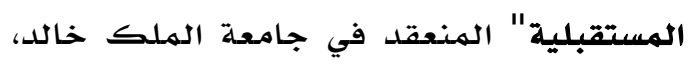

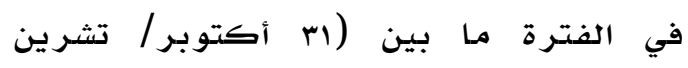

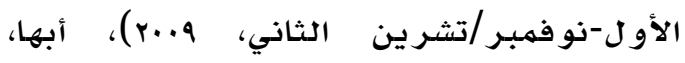
المـملكة العربية السعودية. 


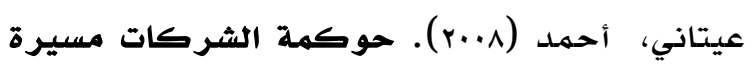

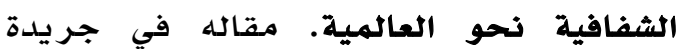

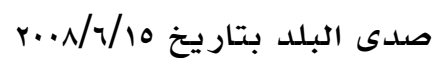

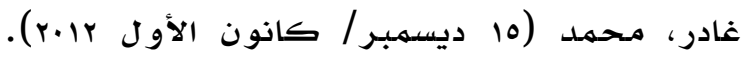

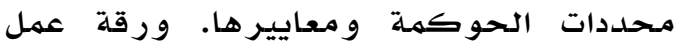

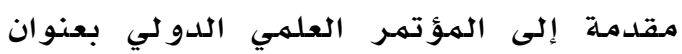

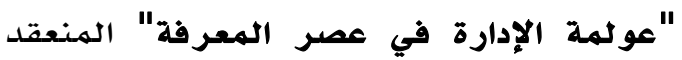

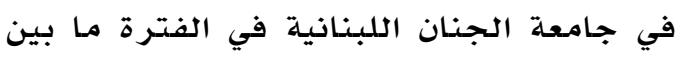

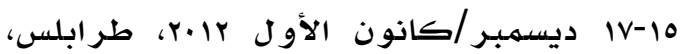
لبنان.

غرابة، صالح (.l. (r). مدى تطبيق مبدأ الإفصاح و الشفافية من مبادئ حوكمة الشركات في شركة بئر المدور المساهمة المحلدودة. رسالة ماجستير غير منشورة: جامعة النجاح الوطنية، نابلس، فلسطين.

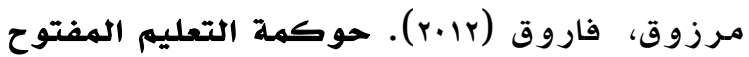

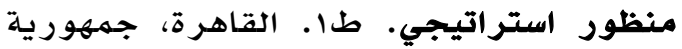
مصر العربية: مكتبة الأنجلو المصرية.

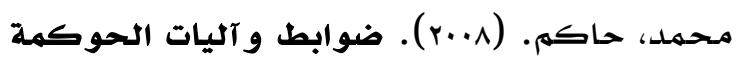

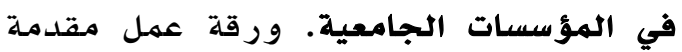
إلى المؤتمر العربي الثاني للجامعات العربية-

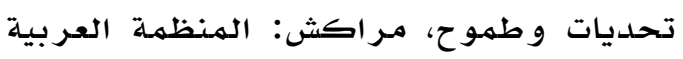

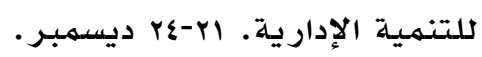

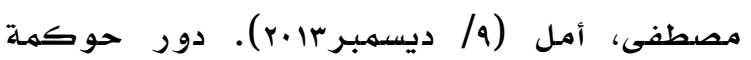

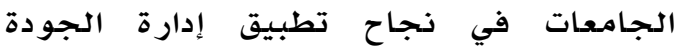
الشاملة. ورقة عمل مقدمـة إلى "المؤتمر إلى السنوي الثالث عشر حالة الحوكمة والإدارة العامة في الدول العربية خيارات ام تحديات

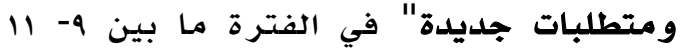
ديسمبر rا..r، فندق رويال، عمان، الأردن. ناصر الدين، يعقوب (r|rr). إطار نظري مقترح

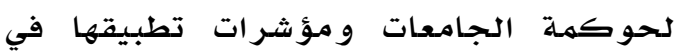
ضوء متطلبات الجودة الشاملة. مجلة تطوير

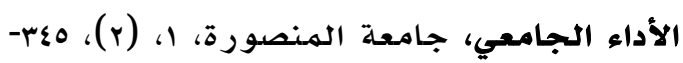
.rvo

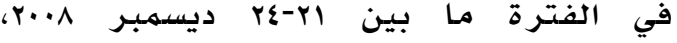
مر اكش، المغرب.

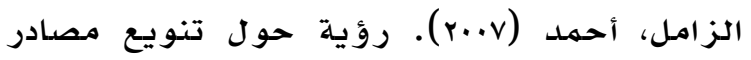

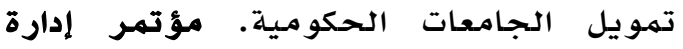

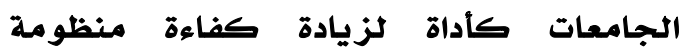

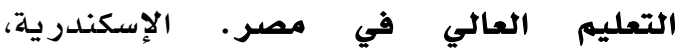
جمهورية مصر العربية: مكتبة الإسكندرية.

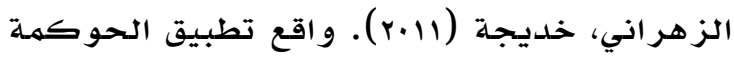

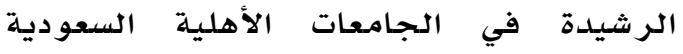

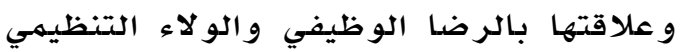
لأعضاء هيئة التدريس فيها. رسالة دكتوراه

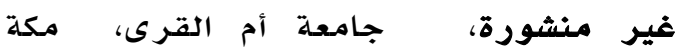
المكر مة، المملكة العربية السعودية.

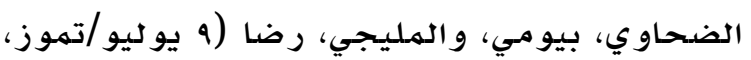

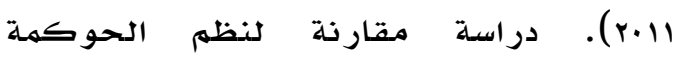

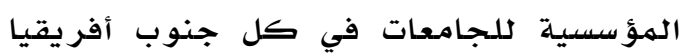

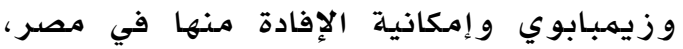

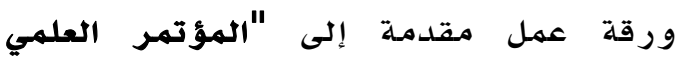
التاسع عر للجمعية المصرية للتربية

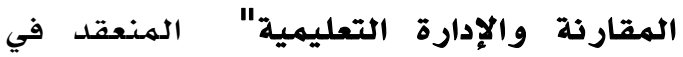

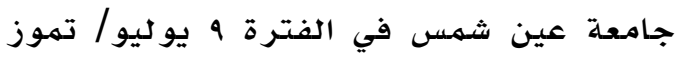
11.r، القاهرة، جمهورية مصر العربية.

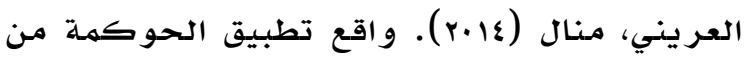
وجهة الظر العضاء الهيئتين الإدارية

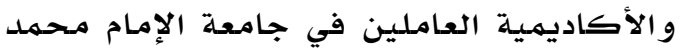
بن سعود الإسلامية. المجلة التربوية الدولية الدية

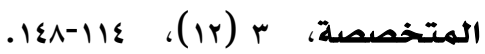

العشماوي، خليل (1...r). الحوكمة المؤسسية. القاهرة: مكتبة الحرية للنشر والتوزيع.

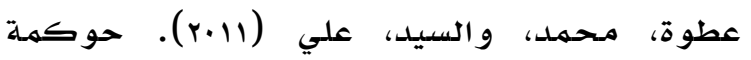
النظام التعليمي مدخل لتحقيق الجودة في

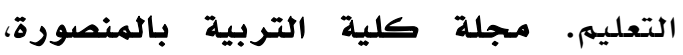

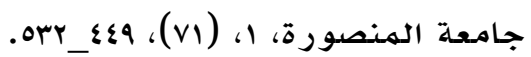
علي، عبد الوهاب؛ وشحاته، شحاته (r..v). مراجعة الحسابات وحوكمة الشركات في ولئ بيئة الأعمال العربية والدولية المعاصاتة وحرة.

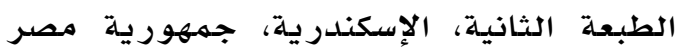
العربية: مكتبة الدار الجامعية. 
Acemoglu, D., Johnson, S., \& Robinson, J. (2001). The colonial origins of comparative development: An empirical investigation. The American Economic Review, 91 (5), 13691401.

Alamgir, M. (May 7, 2007). Corporate governance: A risk perspective. Paper presented at "Corporate governance and reform: Paving the Way to financial stability and development" Conference organized by the Egyptian Banking Institute, Cairo, May $7-8,2007$.

Beg, N., \&. Ashok, A. (2015). Development and sustenance of efficient governance in universities - An exploratory study. ABHINAV International Journal of Research in Management E Technology, 4 (5), 83-92.

Bratianu, C., Reinhardt, Z., \& Almasan, O. (2010). Practice models and public policies in the management and governance of higher education, Transylvanian Review of Administrative Sciences, 29E, 39-50.

Cattrysse, J. (2005). Reflections on corporate governance and the role of the internal auditors. Roeselare, Belgium: Roularta Media Group. Available on www.ssrs.com

Corcoran, S. (2004). Duty, discretion and conflict: University governance and the legal obligations of university boards. Australian Universities' Review, 46 (2), 3037.

Deininger, K. \& Mpuga, P. (2005). Does greater accountability improve the quality of public service delivery? Evidence from Uganda, World Development, 33 (1), 171101.

Ferraz, C., \& Finan, F. (2011). Electoral accountability and corruption: Evidence from the audits of local governments. American Economic Review, 101 (4), 12741311.

Freund, C., Rijkers, B., \& Nucifora, A. 2014, "All in the Family: State Capture in Tunisia," World Bank Policy Research Working Paper 6810 (Washington: World Bank).

Graham, J., Amos, B., \& Plumptre, T. (2003). principles for good governance in the 21st, century: Policy Brief No.15. Ottawa, Canada: The Institute On Governance (IOG).
Hall, R., \& Jones, C. (1999). “Why Do Some Countries Produce So Much More Output per Worker than Others? Quarterly Journal of Economics. 114 (1), 83-116.

Henard, F., \& Mitterle, A. (2010). Governance and quality in higher education. A review on governance arrangements and quality assurance guidelines. Paris, France: OECD.

Irtwange, S., \& Orsaah, S. (2010). Assessment of groups influence on management style as related to university governance. Educational Research and Reviews, 5 (2), 4663.

Kaufman, D., Kraay, A. \& Zoido P. (1999). Aggregating governance indicators. World Bank Policy Research Working Paper 2196 (Washington: World Bank).

Kaufman, R. (1982). Identifying and Solving Problems: A System Approach. 3rd, ed. San Diego: University Associates.

Krupar, C., \& Cook, S. (June 10, 2010). The voiceless majority: A pair docs on paradox and changing demographics in The American professorate related to shared governance. Paper Presented at the American Association of University Professors Annual National Conference (Jun 10, 2010), Washington, DC, US.

Lee, L-S., \& Land, M. (2010). What university governance can Taiwan learn from the United States? Paper published in the proceedings of the International Presidential Forum (pp197-187).

Lokuwaduge, S., Sriyani, C., \& Armstrong, A. (2015). An evaluation of governance mechanisms as determinants of performance: A case study of Australian universities. Evaluation Journal of Australasia. 15 (2), 22-32.

Shattock, M. (2013). University Governance, Leadership and Management in a Decade of Diversification and Uncertainty. Higher Education Quarterly Special Issue: Governance Revisited. 67 (3), 217-233.

Wang, L. (2010). Higher Education Governance and University Autonomy in China. Globalization, Societies and Education, $8(4), 477-495$. 


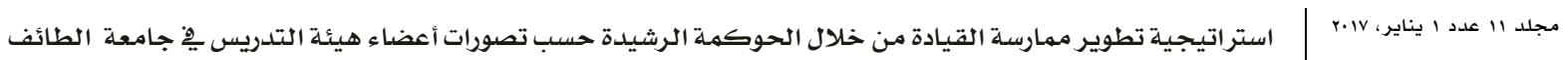
ليلى أبو العلا

ملحق ا. تفاصيل درجة الممارسة والأهمية لفقرات أبعاد القيادة من خلال الحوكمة الرشيدة

\begin{tabular}{|c|c|c|c|c|c|c|c|}
\hline درجة الممارسة & الانحراف & المتوسط & 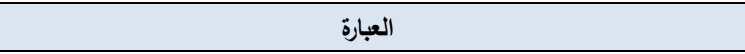 & درجة الممارسة & 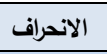 & المتوسط & \multirow{2}{*}{$\overline{7}$} \\
\hline \multicolumn{3}{|c|}{ درجة الممارسة تنازليا } & & \multicolumn{3}{|c|}{ درجة الممارسة } & \\
\hline عالية &. $.0 \mathrm{~V}$ & r.o乏 & توفر الجامعة قاعدة بيانات عن كافة العاملين & عالية &. .01 & $r .74$ & \multirow{8}{*}{ 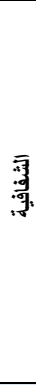 } \\
\hline عالية &. $.0 \mathrm{r}$ & $r . \varepsilon r$ & تحدث الجامعة المعلومات على الموقع الإلكتروني باستمرار & عالية & $. .0 \leqslant$ & $r .71$ & \\
\hline متوسطة &.$\vee \vee 9$ & $1 . \wedge \mathrm{V}$ & تعلن الجامعة عن معايير شغل الوظيفة بكل وضوح & عالية &. .07 & r.74 & \\
\hline متوسطة &. $.7 r$ & 1.14 & تفصح الجامعة عن سياستها المتبعة في منح العلاوات لجميع المنتفعين & عالية & $.0 \mathrm{r}$ & r.१^ & \\
\hline متوسطة &. $.7 r$ & 1.10 & تقدم الجامعة تغذية راجعة عن تحليل البيئة الداخلية والخارجية للجميع & عالية &..$\leqslant \wedge$ & r.VI & \\
\hline منوسطة &. .14 & l.גז & توزع الجامعة دليلا واضحا للأنظمة والقوانين لجميع العاملين & عالية & 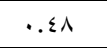 & T.VV & \\
\hline متوسطة & .7 & $1 . \wedge$ & تدعم الجامعة الإعلان عن نتائج الأداء مبينة نقاط القوة والضعف & عالية &..$\leqslant \varepsilon$ & r.v & \\
\hline منوسطة &. .70 & 1.174 & توفر الجامعة نظام إعلام يوضح جميع الاستفسارات حول تطبيق الأنظمة والقوانين & عالية &.$r \Lambda$ & r.AV & \\
\hline 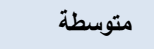 & $\because \mathrm{r \Lambda}$ & 1.91 & 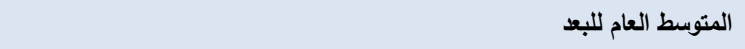 & عالية & $\ldots 9$ & r.VY & \\
\hline عالية &. $.7 r$ & $r .71$ & تشكل الجامعة لجانا مشتركة بين الأقسام لاعم العمل التشاركي & عالية &. $.0 \mathrm{~V}$ & r.VI & \\
\hline عالية &. .79 & r.£^ & تطبق الجامعة مبدأ الثورى في إدارة أنشطة الكليات الدختلفة & عالية & .0 & r.T4 & \\
\hline عالية &. .71 & t.rV & تثارك الجامعة العاملين في صياغة الإطار المفاهيمي لها & عالية &. .01 & r.70 & \\
\hline منوسطة & $. .0 \leqslant$ & r... 9 & تختار الجامعة أعضاء المجالس العلمية بالانتخاب & عالية & 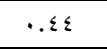 & r.A. & \\
\hline متوسطة &. .07 & r... & تتعامل الجامعة بالاقتراحات المقدمة لها بمهنية عالية & عالية & $\cdot . \leqslant 9$ & r.vo & \\
\hline متوسطة &. .14 & 1.91 & تسمح الجامعة بتعديل القرارات بعد مناقشتها من قبل المعنيين بها & عالية & $\cdot . \leqslant 7$ & r.A. & \\
\hline منخفضة & $.7 \leqslant$ & 1.74 & تسمح الجامعة بمشاركة المعنيين في صناعة القرار & عالية & $\cdot . \leqslant 7$ & r.Vฯ & \\
\hline منخفضة &. $.0 \mathrm{~V}$ & 1.70 & يشارك العاملون في تقييم القيادات الإدارية والأكاديمية & عالية & $\therefore \varepsilon$ & 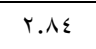 & \\
\hline متوسطة & - rr & r.1. & المتوسط العام للبعد المبام & عالية الية & $\ldots v$ & r.vo & \\
\hline عالية &. .01 & r. $\leqslant \varepsilon$ & تتابع الجامعة التقارير الدورية المنبثقة عن لجان المراجعة الداخلية & عالية & $\cdots \varepsilon \vee$ & $r . v \varepsilon$ & \multirow{8}{*}{$\begin{array}{l}\overline{3} \\
\frac{3}{3} \\
\text { s. }\end{array}$} \\
\hline عالية & $.0 \mathrm{r}$ & r. $\varepsilon \varepsilon$ & تطبق الجامعة المساءلة لتحقيق الجودة & عالية & .0 & r.vr & \\
\hline عالية & .7 & T.YT & تمنح الجامعة استقلالية للجان المراجعة الداخلية & عالية & $.0 \mathrm{r}$ & $r .71$ & \\
\hline متوسطة & .7 & r..T & تعلن الجامعة عن سياستها المنبعة في الرقابة الداخلية & عالية & $\cdot . \leqslant r$ & t.AT & \\
\hline منوسطة &. .09 & r..r & توفر الجامعة إدارة خاصة لرقابة الأداء بشكل مستمر & عالية &..$\leqslant 1$ & T.Ar & \\
\hline متوسطة & 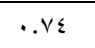 & I.vA & تعلن الجامعة عن الأسس المتبعة في مساءلة أعضاء هيئة التنريس عن أدائهم & عالية & $.0 \mathrm{r}$ & T.乏० & \\
\hline منوسطة & $.7 \varepsilon$ & $1 . \mathrm{Vo}_{0}$ & توجه الجامعة المساعلة دون تمييز للمركز الوظيفي عند حدوث الانحرافات في الأداء & عالية &. $\mathrm{r} \Lambda$ & r.Ao & \\
\hline منخفضة &. .71 & $1.7 \varepsilon$ & تفعل الجامعة نظام مساءلة لمجالس الكليات فيما يتعلق بالأداء والنتائج المتوقعة & عالية & $\therefore \varepsilon$ & r.ی4 & \\
\hline متوسطة &.$\mu$ & r... & 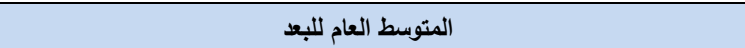 & عالية & .11 & r.v & \\
\hline عالية &. .01 & r.£ & توفر الجامعة شروط الترقية ضمن معايير واضحة لجميع العاملين & عالية &. .07 & r.V. & \multirow{8}{*}{$\begin{array}{l}\overline{3} \\
\overline{3} \\
\overline{3} \\
\overline{3}\end{array}$} \\
\hline متوسطة &. $.0 \mathrm{r}$ & r... & توازن الجامعة بين السلطات والصلاحيات لثاغل الوظيفة & عالية & $.0 \mathrm{r}$ & r.7. & \\
\hline متوسطة &. .7 & r..V & توفر الجامعة حوافزا للمتميزين حسب معايير محددة & عالية &. $.0 \mathrm{~V}$ & r.01 & \\
\hline متوسطة & .7 & r...o & تحدد الجامعة معاييرا واضحة لمنح المكافآت للعاملين بمختلف المسنويات الإدارية & عالية & $. .0 \leqslant$ & r.os & \\
\hline منوسطة &. .09 & r...o & تمنح الجامعة الفرص ذاتها أمام من تتحقق فيهم معايير شغل الوظيفة & عالية &. .0 & T.Vo & \\
\hline متوسطة &.$v \varepsilon$ & r... & تتسم معايير نقييم الأداء المتبعة في الجامعة بالمساواة & عالية & $.0 \mathrm{r}$ & r.VY & \\
\hline منوسطة &. $.7 \varepsilon$ & r... & تنتبى الجامعة مقترحات الأعضاء في المستويات الإدارية الإجرائية & عالية &. .0 & T.VV & \\
\hline منخفضة &. .71 & 1.70 & تتساوى فرص مشاركة الأقسام النسائية والرجالية في صناعة القرار & عالية &..$\leqslant 0$ & r.VV & \\
\hline متوسطة & $\ldots v$ & r... & المتوسط العام للبعد & عالية & $\ldots 9$ & r.१^ & \\
\hline عالية &. .01 & r.07 & تعمل الجامعة على تشكيل فرق عمل لإنجاز المهام & عالية &.$r \Lambda$ & r.Av & \multirow{8}{*}{ 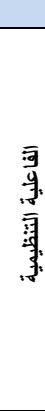 } \\
\hline عالية &..$\leqslant 9$ & r.YT & تمنح الجامعة إجازات علمية لأعضائها للتفرغ العلمي & عالية & $\cdot . \varepsilon r$ & r.A. & \\
\hline عالية &. $.0 \mathrm{~V}$ & r.ro & تحرص الجامعة على استقطاب المتميزين من الإداريين والأعضاء الأكاديميين & عالية &..$\leqslant 7$ & r.vq & \\
\hline عالية &.$+\pi$ & T.rT & تعمل الجامعة على تحقيق أهدافها ضمن نقطة مثلى( أقل وقت وجهـ وكلفة ممكنة) & عالية & 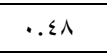 & r.VA & \\
\hline منوسطة &.$\cdot 1$ & r... & تشجع الجامعة العاملين فيها على التطور الذاتي & عالية & $\cdot . \leqslant \Lambda$ & r.VY & \\
\hline متوسطة &. $.7 \wedge$ & $1.9 \mathrm{~V}$ & تعكس أهداف الجامعة طموحات العاملين على اختلاف مستوياتهم الإدارية & عالية & $.0 \mathrm{or}$ & r.0ई & \\
\hline منوسطة &. .09 & 1.97 & تعزز الجامعة مشاعر الانتماء عند العاملين نحو الجامعة & عالية &.$r \varepsilon$ & r.9. & \\
\hline منخفضة &..$v 1$ & $1.7 \varepsilon$ & توفر الجامعة التدريب الذي يلبي حاجات العاملين & عالية &.$r \varepsilon$ & r.91 & \\
\hline متوسطة &. .19 & r.11 & المتوسط العام للبعد & عالية & $\ldots \varepsilon$ & r.vq & \\
\hline متوسطة & $\ldots 0$ & r.. 4 & الأداة ككل & عالية & $\ldots \varepsilon$ & r.V $\varepsilon$ & \\
\hline
\end{tabular}


ملحق r. حاجة ممارسة أبعاد القيادة من خلال الحوكمة الرشيدة في جامعة الطائف

\begin{tabular}{|c|c|c|c|c|}
\hline \multicolumn{2}{|c|}{ الدرجة المرغوبة } & \multirow{2}{*}{ متوسطة الارجة الحالية } & \multirow{2}{*}{ متوسط البعد } & \multirow{2}{*}{ الثبافية } \\
\hline عالية & 4 & & & \\
\hline عالية & & 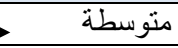 & تعلن الجامعة عن معايير شغل الوظيفة بكل وضوح & \\
\hline عالية & & متوسطة & تفصح الجامعة عن سياستها المتبعة في منح العلاو ات لجميع المنتفعين & \\
\hline عالية & & منوسطة & تقدم الجامعة تغذية راجعة عن تحليل البيئة الداخلية والخارجية للجميع & \\
\hline عالية & 4 & متوسطة & توزع الجامعة دليلا و اضحا للأنظمة و القو انين لجميع العاملين & \\
\hline عالية & & متوسطة & تدعم الجامعة الإعلان عن نتائج الأداء مبينة نقاط القوة و الضعف & \\
\hline عالية & & 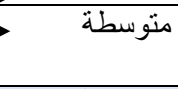 & و القو انين الجامعة نظام إعلام يوضح جميع الاستفسار ات حول تطبيق الأنظمة & \\
\hline عالية & & 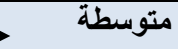 & متوسط البعد & المشاركة الفاعلة \\
\hline عالية & 4 & متوسطة & تسمح الجامعة بتعديل القرار ات بعد مناقثتها من قبل المعنيين بها & \\
\hline عالية & & 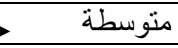 & تختار الجامعة أعضاء المجالس العلمية بالانتخاب & \\
\hline عالية & 4 & متوسطة & تتعامل الجامعة بالاقتر احات المقدمة لها بمهنية عالية & \\
\hline عالية & & منخفضة & يشارك العاملون في تقييم القيادات الإدارية و الأكاديمية & \\
\hline عالية & & منخفضة & تسمح الجامعة بمشاركة المعنيين في صناعة القرار & \\
\hline عالية & & متوسطة & متوسط البعد & 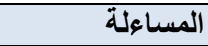 \\
\hline عالية & & متوسطة & تعلن الجامعة عن سياستها المنبعة في الرقابة الداخلية & \\
\hline عالية & & متوسطة & توفر الجامعة إدارة خاصة لرقابة الأُداء بشكل مستمر & \\
\hline عالية & $\leftarrow$ & 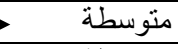 & تعلن الجامعة عن الأسس المتبعة في مساءلة أعضاء هيئة التدريس عن أدائهم & \\
\hline عالية & 4 & متوسطة & الأداء جه الجامعة المساءلة دون تمييز للمركز الوظيفي عند حدوث الانحر افات في & \\
\hline عالية & & متوسطة & تعلن الجامعة عن سياستها المتبعة في الرقابة الداخلية & \\
\hline عالية & & منخفضة & تفعل الجامعة نظام مساءلة لمجالس الكليات فيما يتعلق بالأداء و النتائج المتوقعة & \\
\hline عالية & 4 & متوسطة & متوسط البعد & 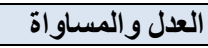 \\
\hline عالية & & متوسطة & جميع فقر ات البعد باستثناء و احدة & \\
\hline عالية & & منخفضة & تتساوى فرص مشاركة الأقسام النسائية و الرجالية في صاعة القر ار & \\
\hline عالية & & متوسطة & متوسط البعد & الفاعلية التنظيمية \\
\hline عالية & & متوسطة & تشجع الجامعة العاملين فيها على التطور الذاتي & \\
\hline عالية & & 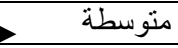 & تعكس أهداف الجامعة طموحات العاملين على اختلاف مستوياتهم الإدارية & \\
\hline عالية & & متوسطة & تعزز الجامعة مشاعر الانتماء عند العاملين نحو الجامعة & \\
\hline عالية & $\longleftarrow$ & منخفضة & توفر الجامعة التدريب الذي يلبي حاجات العاملين & \\
\hline عالية & $\longleftarrow$ & 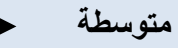 & المتوسط الكلي للأداة & 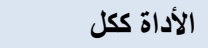 \\
\hline
\end{tabular}

